\title{
Synchrotron-based FTIR microspectroscopy for the mapping of photo-oxidation and additives in acrylonitrile-butadiene-styrene model samples and historical objects
}

\author{
Daniela Saviello $^{\mathrm{a}, *}$, Emeline Pouyet ${ }^{\mathrm{b}}$, Lucia Toniolo $^{\mathrm{a}}$, Marine Cotte ${ }^{\mathrm{b}, \mathrm{c}}$, Austin Nevin ${ }^{\mathrm{d}}$ \\ a Politecnico di Milano, Dipartimento di Chimica Materiali e Ingegneria Chimica, Piazza Leonardo da Vinci, 26-20133 Milano, Italy \\ ${ }^{\mathrm{b}}$ European Synchrotron Radiation Facility, Polygone Scientifique Louis Néel, 6 rue Jules Horowitz, F-38000 Grenoble, France \\ ${ }^{\mathrm{c}}$ Laboratoire d'archéologie Moléculaire et Structurale, LAMS, UMR 8220, CNRS, F-75005 Paris, France \\ d Consiglio Nazionale delle Ricerche - Istituto di Fotonica e Nanotecnologie (CNR-IFN), Dipartimento di Fisica, Politecnico di Milano, \\ Piazza Leonardo da Vinci 32, Milano 20133, Italy
}

H I G H L I G H T S

- We developed a novel sample preparation method for ABS.

- We developed a novel characterization of ABS degradation using SR-FTIR mapping.

- We studied ABS degradation by high resolution $\left(3 \times 3 \mu \mathrm{m}^{2}\right)$ molecular maps.

- We studied the spatial distribution of microscopic additives within ABS.

- We identified inclusions of proteinaceous material in historic objects made in ABS.

\section{A R T I C L E I N F O}

\section{Article history:}

Received 18 April 2014

Received in revised form 10 July 2014

Accepted 13 July 2014

Available online 19 July 2014

\section{Keywords:}

Synchrotron-Fourier transform infrared microspectroscopy

Additives

Acrylonitrile-butadiene-styrene

Cultural heritage

Polymer degradation

Mapping
G R A P H I C A L A B S T R A C T

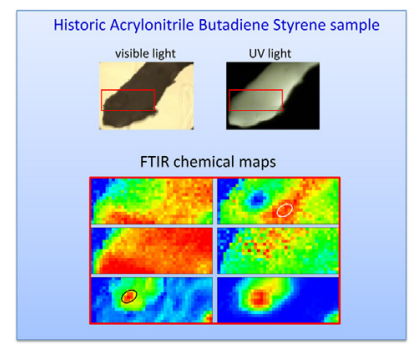

\section{A B S T R A C T}

Synchrotron-based Fourier transform infrared micro-spectroscopy (SR- $\mu$ FTIR) was used to map photooxidative degradation of acrylonitrile-butadiene-styrene (ABS) and to investigate the presence and the migration of additives in historical samples from important Italian design objects. High resolution $\left(3 \times 3 \mu \mathrm{m}^{2}\right)$ molecular maps were obtained by FTIR microspectroscopy in transmission mode, using a new method for the preparation of polymer thin sections. The depth of photo-oxidation in samples was evaluated and accompanied by the formation of ketones, aldehydes, esters, and unsaturated carbonyl compounds. This study demonstrates selective surface oxidation and a probable passivation of material against further degradation. In polymer fragments from design objects made of ABS from the 1960s, UV-stabilizers were detected and mapped, and microscopic inclusions of proteinaceous material were identified and mapped for the first time.

\footnotetext{
* Corresponding author. Tel.: +39 0223993143.

E-mail address: daniela.saviello@polimi.it (D. Saviello).
}

\section{Introduction}

Plastics are found everywhere in museums and private collections of modern and contemporary artefacts. Since their early production, they represented, and represent today, new 
possibilities for designers, architects and artists thanks to their excellent properties as well as the great versatility and predisposition for experimentation. Cellulose-based materials, plasticized polyvinyl chlorides, polyether-based polyurethanes, polyvinyl esters, polystyrene-based materials are among the most used materials to create sculpture, design objects, architectural models, decorative arts.

However, the conservation of these artefacts is complex and challenging because of the short lifetime of plastics and their very wide range of aging behaviors, display and storage requirements [1]. Degradation mechanisms can involve both thermal and oxidative processes as consequence of excessive exposure to light, heat, moisture, chemicals, gaseous and particulate pollutant, mechanical stress, migration and evaporation of additives [2]. Hence, before developing a conservation strategy, a complete study of standard materials and an assessment of the chemical conditions of case studies are needed. In this work we describe the results of the study of one of the most important polymers used in design, acrylonitrile-butadiene-styrene (ABS). ABS has found important applications in design, and historical objects made in ABS are today found in international museums and collections as design objects or household items, such as telephones, domestic appliances, rigid luggage and piping, as well as lamps and musical instruments $[3,4]$.

ABS is a graft copolymer made of an acrylonitrile-styrene continuous phase (SAN) and partially grafted polybutadiene (PB) that acts as an impact modifier, giving excellent mechanical properties to the material (Fig. 1).

For over 50 years ABS has been widely used in industrial applications due to its excellent mechanical, thermal, chemical, and electrical properties that can be modified by changing grafting conditions and monomer amount [5]. Nevertheless, ABS is susceptible to photo-oxidative degradation. This instability often leads to the alteration of its physical properties, chemical modifications such as crosslinking and chain scission, color changes and worsening of mechanical performance. The susceptibility of $A B S$ to photo-oxidative degradation is due to the butadiene, and, in particular, to the presence of residual double bonds along the polymer chains, which lead to molecular modifications localized preferentially on material surface [6]. This degradation generally involves an autocatalytic free radical chain mechanism where the allylic radicals react with oxygen to form hydroxide products. Labile oxygen-oxygen bonds break to form $\mathrm{RO}^{\bullet}$ radicals, precursor of typical oxidation product such as aldehydes, ester, carboxylic acids and ketones [7]. The penetration of radiation and oxygen into the material will directly impact the depth of the degradation.

Some research has been dedicated to understanding oxidation as a function of depth and wavelength in $\mathrm{ABS}$, which are important for the suitable choice of stabilizers in the formulation of the

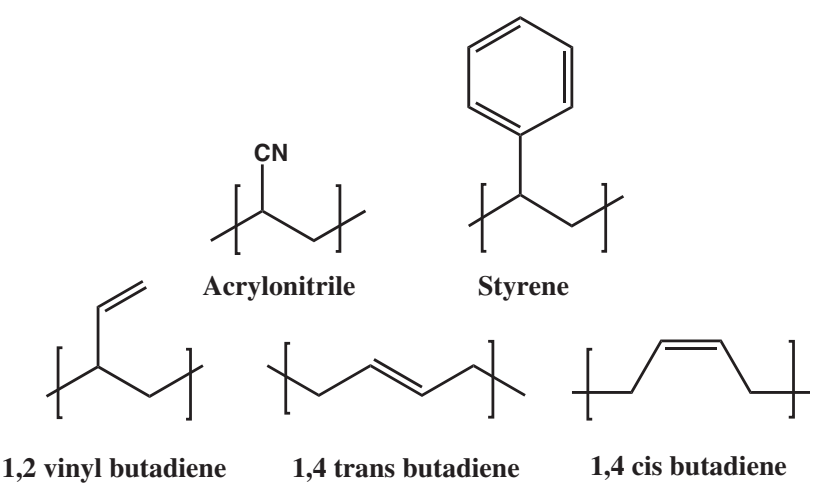

Fig. 1. Repeating structural units in acrylonitrile-butadiene-styrene (ABS). material, and for better understanding ways of limiting oxidation as a result of light exposure. Pioneering research was carried out by Bokria and Schlick, in order to obtain primary in-depth information about the photo-degradation of ABS [8]. For the study a microtome was used to slice the irradiated block materials, along the sample surface, with incremental steps of 50 and $150 \mu \mathrm{m}$. The thin sections were then dissolved in chloroform and the solutions analyzed with Fourier transform infrared (FTIR) spectroscopy in attenuated total reflectance (ATR) mode [8]. FTIR is perfectly suited for the chemical characterization of such molecular modifications: through the vibrational excitation of most of the molecular groups, it allows the simultaneous identification of reactive functions (decreasing intensity), and degradation products (increasing intensity). In this case, the depth-resolution was limited by the slicing procedure. The authors demonstrated that the main degradation occurs in the first $50 \mu \mathrm{m}$. They also noticed that, for long exposure time, the irradiated surface causes embrittlement and hardening of the polymer. Hence, microtoming of the first slices was particularly difficult, and in some cases, the first sections were sliced with a thickness of about $100 \mu \mathrm{m}$. In summary, this work provides a major reference regarding the characterization of the photo-degradation of ABS. It is a first attempt to combine an in-depth approach to FTIR spectroscopy. It also demonstrates that such samples require much higher in-depth resolution.

An alternative to the serial slicing of a polymer block along its surface is the preparation of thin sections perpendicular to the sample surface with a microtome. This approach can reveal the full stratigraphy of the material in a single slice. Such thin sections can be studied using FTIR microscopy where individual spectra are acquired (consecutively in a raster mode, or simultaneously with a 2D detector) over a line or a 2D map. As an example, FTIR microscopy was used to study the thermo-oxidative degradation of hydroxyl-terminated polybutadiene/isophorone diisocyanate polyurethane rubber [9]. In these experiments, the beam size was set to $40 \times 120 \mu \mathrm{m}^{2}$. The degradation induced by oxygen was found to penetrate the polymer over $2 \mathrm{~mm}$, accordingly a resolution of $40 \mu \mathrm{m}$ was sufficient to image the degradation profile. Photo-oxidation of ABS exposed to UV radiation occurs only to a depth of a few tens of microns below the surface and therefore requires imaging techniques with high lateral resolution. Here, we propose to tackle this problem by combining the sensitivity of FTIR spectroscopy to high resolution microscopy provided by synchrotron radiation (SR) source for the analysis of thin-sections of ABS from model and historical samples.

SR- $\mu$ FTIR is a powerful analytical tool that offers new opportunities for the study of materials and is particularly suitable for the analysis of micrometer-sized samples of polymers; examples of SR- $\mu$ FTIR analyses on reflectance mode of model polymer samples demonstrate the potential of the technique for the analysis of multi-layered materials at high spatial resolution [10]. The synchrotron photon source is highly-coherent, collimated, and with an extended spectral distribution. This aspect is essential for spectroscopic analysis. Compared to conventional global sources, SR- $\mu$ FTIR has an excellent brightness thanks to a smaller source size and narrow range of emission angles which result in a signal/noise ratio 1000 times better [11,12]. By coupling SR infrared radiation and FTIR micro-spectroscopy, mapping analysis can be carried out with micrometric resolution. Images can be obtained by two ways. In a conventional scanning way, point-by-point spectra are recorded successively in a defined area of a sample which is raster scanned by moving the sample stage. Recently, a full-field approach was proposed, where the sample is static, illuminated by the combination of 12 parallel collimated beams and the images are obtained thanks to a 2D detector [13]. There are many examples of applications of SR- $\mu$ FTIR in different fields which range from the study of biology and biomaterials (cells 
and tissues) [14,15] to inorganic materials (geological samples) $[16,17]$, from cultural heritage (paintings, archaeological samples) $[18,19]$ to materials engineering (high pressure materials and ion-selective electrodes) [20,21], but there are fewer applications for the analysis of polymers $[13,22-26]$. SR- $\mu$ FTIR microspectroscopy is particularly suited for the study of micro-patterned biodegradable copolymers, oriented semi-crystalline polymers and multilayered materials and is powerful for the analysis of heterogeneities and inclusions within different kinds of materials including polymers, minerals or biological samples [25,26]. Not only the composition of polymeric materials can be assessed, but also the molecular configuration, the conformation and the orientational properties of polymer chains.

Sampling of historical objects is a critical issue; fragments are generally small, with smooth, colored and delicate surfaces and, for conservation purposes, only micro-sampling is allowed. The analysis of micro-samples is a significant challenge and in this context SR- $\mu$ FTIR microspectroscopy presents an additional asset since it requires only micro-sampling [27]. In this work, two types of samples were studied: a set of photo-aged standard ABS specimen and fragments from two historical Italian design objects from the 1960s. Accelerated photo-oxidative aging was performed on standard samples of ABS in order to simulate, in a suitably short time, the photo-oxidation of the material and to understand and map the chemical reactions involved. The two design objects from a private collection were studied: the Grillo telephone, designed by Marco Zanuso and Richard Sapper for Siemens in 1967, and the E63 lamp designed by Umberto Riva for Francesconi in 1963 (Fig. 2).

Grillo was the first phone to be made in plastic, with the receiver and the disc housed in the same small unit, and won the "Compasso d'oro" prize in 1967. E63 was one of the first table lamps made in plastic with swiveling cap and became a design icon in the 1960s.

\section{Materials and methods}

\subsection{Standard acrylonitrile-butadiene-styrene samples}

Commercial uncolored acrylonitrile-butadiene-styrene (ABS) beads (Lanxess Srl, Milano) were extruded in the laboratory of CESAP, Centro Europeo Sviluppo Applicazioni Plastiche. The specimens were prepared according to the normative ISO 527:2009 for tensile testing, nominally $4 \mathrm{~mm}$ thick with a gauge section $80 \mathrm{~mm}$ long and $10 \mathrm{~mm}$ wide. In the text, the abbreviation ABS will be used in place of acrylonitrile-butadiene-styrene.

\subsection{Artificial ageing of acrylonitrile-butadiene-styrene samples}

Photo-oxidative aging of standard samples was carried out following the normative Italian UNI 10925:2001 for artificial solar light test. A Suntest CPS+ apparatus was used (Heraeus, Germany) equipped with a xenon arc lamp source and a cut off filter for wavelengths below $290 \mathrm{~nm}$. Irradiation was kept constant at $765 \mathrm{~W} \mathrm{~m}^{-2}$, at a distance of $20 \mathrm{~cm}$, and the temperature was maintained at $53^{\circ} \mathrm{C}$. Different specimens were aged at different intervals of time for up to $1000 \mathrm{~h}$.

\subsection{Colorimetric analysis}

Colorimetry was carried out with a Konica Minolta CM-600D Spectrophotometer, equipped with a pulsed xenon lamp (UV cut filter) light source at $8^{\circ}$ and automatic white balance correction on model samples without sample preparation. Color data are reported according to CIE Lab coordinate system. Color parameters were measured in both the SCE (specular component excluded) and SCI (specular component included) configurations.

\subsection{Scanning electron microscopy (SEM)}

SEM was carried out with a Zeiss EVO 50 EP environmental scanning electron microscope(ESEM), equipped with an Oxford INCA 200-Pentafet LZ4 spectrometer. Analyses were carried out directly on the surface of fragments, without any specific sample preparation.

\subsection{Samples from historical objects}

Microscopic samples were taken from different areas of the objects using a scalpel. The samples were taken from external sides and from areas which would not compromise the conservation of the objects

\subsection{SR-FTIR mapping in transmission mode}

\subsubsection{Sample preparation}

Sample preparation is usually a critical step for $\mu$ FTIR analysis, all the more so when working in transmission mode. In such a case,
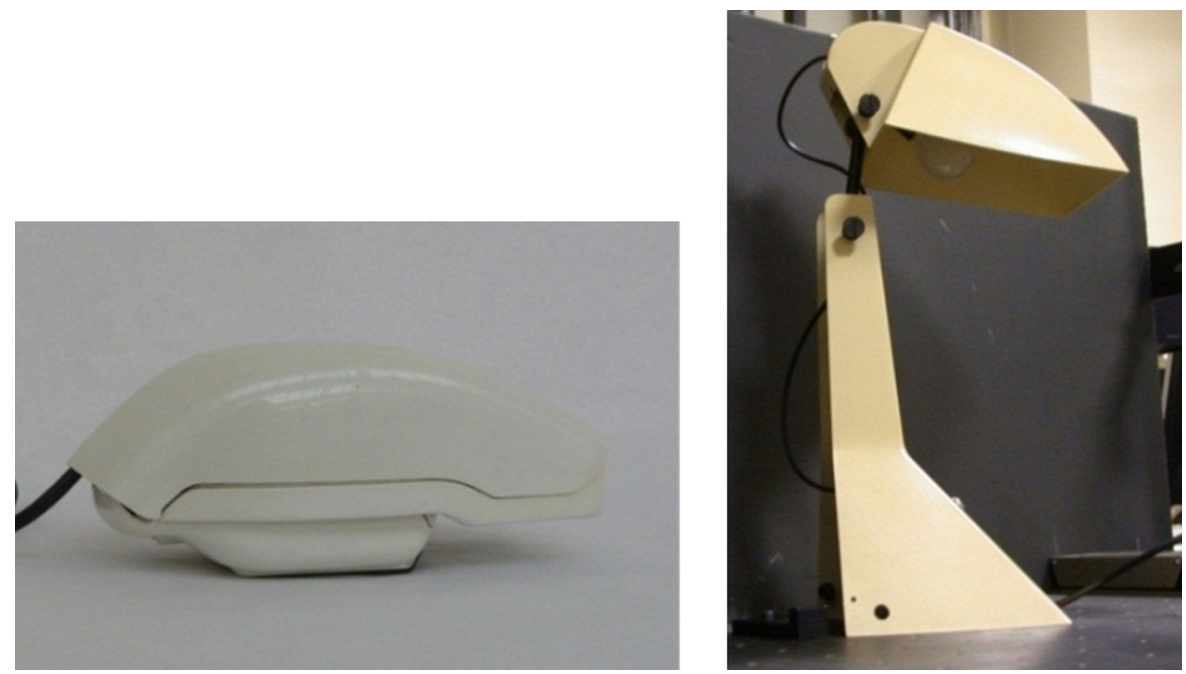

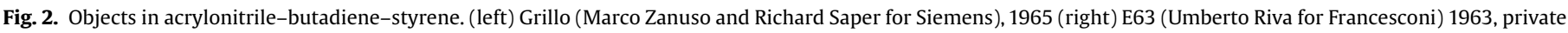
collection. 
it is necessary to obtain very thin sections (1-4 $\mu \mathrm{m})$ of the sample to avoid over-absorption of the transmitted beam. Cross-sections and thin-sections of samples are generally prepared by embedding the sample into a casting resin [13]. This can end into spectral interferences, and alternative solutions have been investigated $[28,29]$. Here, a four-step process was adopted and is described below:

1. For ABS standard samples, small fragments of approximately $7 \mathrm{~mm} \times 7 \mathrm{~mm} \times 4 \mathrm{~mm}$ were cut and placed in the sample holder, with the photo aged surface oriented perpendicularly to the microtome knife. For fragments from historical objects, micro-samples were sliced and sandwiched between sacrificial polyethylene sheets and the sandwich was then placed in a specific commercial sample holder before microtoming [29].

2. Slices were obtained using a motorized rotary microtome Leica RM2265 combined to visible microscope, which allows complementary optical observations. Carbide tungsten blades were sufficient during the first trimming step.

3. In order to obtain homogeneous slices thinner than 2 or $3 \mu \mathrm{m}$ the use of a diamond knife was required. A very slow rate of automatic cutting was selected in order to obtain a good, uniform and unbroken thin-section. For each sample of ABS (standard and historical), thin-sections of different thickness were obtained, ranging from 1 to $4 \mu \mathrm{m}$.

4. Curled samples were transferred to a glass slide and were manually resized using a fine scalpel into small flat pieces containing the full sample stratigraphy.

5. For $\mu$ FTIR analyses, sections from artificially photo-aged ABS were sandwiched and analyzed between two $\mathrm{BaF}_{2}$ windows.

6. Sections made from historical objects were additionally compressed between two diamond windows to yield flat and thinner samples. For $\mu$ FTIR analysis, the cell was opened, and the flat samples were analyzed in transmission through one diamond window.

\subsubsection{SR- $\mu$ FTIR microscopy}

SR- $\mu$ FTIR analyses were performed at the ID21 FTIR end-station at ESRF [30,31]. The beam line was designed to exploit the edge radiation emitted from the short straight section (focusing electron lenses) upstream of a bending magnet. A set of a tens of mirrors is used to collect, to collimate, to transfer the beam, and finally to provide a parallel source to the FTIR spectrometer (Nexus, from Thermo). This spectrometer is coupled to a Thermo Continuum microscope that uses reflecting Schwarzschild objectives and a set of apertures to define the spot size. The signal coming from the sample (in transmission or reflection) is detected by a liquid $\mathrm{N}_{2}$ cooled single element MCT detector. In the present experiments, analyses were carried out in transmission, on thin sections and various types of scans were acquired - point analysis, line scans and maps of points. The line-scans and map-scans allow the visualization of the distribution of the main functional groups, in particular the formation and disappearance of some species in the vicinity of the surface.

The beam size was reduced from $10 \times 10 \mu \mathrm{m}^{2}$ down to $3 \times 3 \mu \mathrm{m}^{2}$. In the present case, it was interesting to use an asymmetric beam $\left(10 \times 3 \mu \mathrm{m}^{2}\right)$ in order to have a good balance between flux (10 $\mu \mathrm{m}$ in the direction parallel to the surface) and lateral resolution ( $3 \mu \mathrm{m}$ in the direction perpendicular to the surface). Spectra were acquired as a sum of 10-25 scans depending on the beam size, with a spectral resolution of $4 \mathrm{~cm}^{-1}$, over the $4000-900 \mathrm{~cm}^{-1}$ range.

The microscope is equipped with a white light and a UV light allowing the direct observation of samples in visible and fluorescence modes.
No spectral processing, such as baseline correction and prespectral treatment, was carried out.

\subsubsection{Data analysis}

Data analysis was carried out using the commercial software OMNIC (Thermo) and the open source software PyMca (Python multichannel analyzer) which is developed by the software group of the European Synchrotron Radiation Facility (ESRF) [32]. It allows the selection of regions of interest (ROI) for each functional group and the creation of false color maps which describe the intensity of specific absorption bands. Average spectra over userdefined regions can be calculated, as can intensity profiles from 2D maps. PyMca was also used for statistical analysis of multispectral images and is reported in Supporting Information.

\section{Results and discussion}

\subsection{Color measurements}

In Table $1, \mathrm{~L}^{*}, \mathrm{a}^{*}, \mathrm{~b}^{*}$ values are reported only in SCI mode, as SCE measurements gave similar results. Data demonstrate a strong yellowing after $100 \mathrm{~h}$ of UV exposure which increases slightly after $1000 \mathrm{~h}$. An increase in redness (the $\mathrm{a}^{*}$ parameter), is observed in samples from 100 to $1000 \mathrm{~h}$ exposure.

The yellowing of ABS exposed to UV-A irradiation in the presence of oxygen is a consequence of photo-oxidation. Radical species formed during oxidation of the PB component react with PS in the SAN macrophase, leading to the formation of many highly absorbing products $[6,33]$.

\subsection{Visible, UV and microscopy}

Examination of microtomed samples under the visible and UV fluorescence microscope demonstrated changes in the surface morphology following accelerated aging. The outermost $10-40 \mu \mathrm{m}$ of aged samples are frayed in appearance, which is ascribed to the formation of crazing and micro-cracking of the surface following photo-oxidation [34]. A noticeable fluorescence of the uppermost area of the microtomed aged reference samples under UV excitation allows a primary localization of molecular changes (cf. 4b, 5b, 7b and 8b).

Variable pressure secondary electron SEM images of samples of ABS highlight the crazing of samples following exposure to radiation (Fig. 3). While the unaged samples have a smooth surface, significant crazing of the surface of artificially aged samples is observed; a distribution of large fractures every $\sim 30 \mu \mathrm{m}$ is apparent, with smaller cracks developing perpendicularly along fractures. Crazing thus leads to a greater penetration of radiation and oxygen from the air within the bulk materials.

\subsection{SR- $\mu$ FTIR spectra and maps of unaged standard} acrylonitrile-butadiene-styrene samples

Thin sections samples of standard unaged ABS were analyzed as a reference to assess the native oxidation level in the original

Table 1

$L^{*}, a^{*}, b^{*}$ coordinates of acrylonitrile-butadiene-styrene (ABS in the table) as a function of artificial ageing following exposure to $0,100,500$ and $1000 \mathrm{~h}$ of UV radiation.

\begin{tabular}{llrr}
\hline & $\mathrm{L}^{*}$ & $\mathrm{a}^{*}$ & $\mathrm{~b}^{*}$ \\
\hline ABS 0 h & 85.6 & -3.2 & 8.4 \\
ABS 100 h & 83.7 & -3.8 & 17.5 \\
ABS 500h & 79.1 & -0.5 & 28.4 \\
ABS 1000 h & 74.5 & 1.8 & 30.5 \\
\hline
\end{tabular}




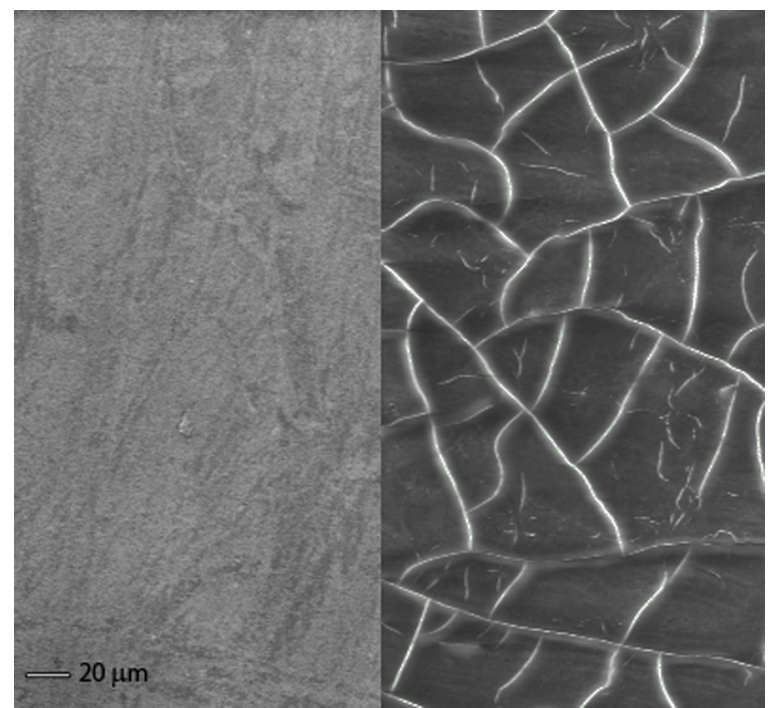

Fig. 3. Variable pressure secondary electron images acquired with scanning electron microscopy of acrylonitrile-butadiene-styrene samples prior to (left) and after $1000 \mathrm{~h}$ (right) photo-oxidative ageing, acquired at $20 \mathrm{kv}, 200 \mathrm{pA}$ at $69 \mathrm{~Pa}$.

material and to evaluate the presence of some additives inside the blend. A SR- $\mu$ FTIR map was recorded. The FTIR spectra demonstrate the homogeneity of the sample (from the outer edge to inside) and three points were taken as reference at three different depths: 15, 85 and $235 \mu \mathrm{m}$ (Fig. 4). These spectra are single pixel data, and show the very good signal to noise ratio obtained in the present conditions.

The assignments of diagnostic bands in the ABS reference are summarized in Table 2 [8,9,35-37].

The weak band at $1732 \mathrm{~cm}^{-1}$ observed in ABS is ascribed to contributions from carbonyl stretching of an ester group. The ester may indicate the presence of an additive in the ABS formulation which could be a heat stabilizer belonging to the class of sterically hindered phenolic antioxidants [6]; another possible explanation is the slight but uniform oxidation of ABS during extrusion [38].
Table 2

Assignment of the main bands in the acrylonitrile-butadiene-styrene FTIR spectrum.

\begin{tabular}{|c|c|c|}
\hline Peak $\left(\mathrm{cm}^{-1}\right)$ & Attribution & $\begin{array}{l}\text { Name and energy range of } \\
\text { the region of interest for } \\
\text { intensity mapping }\left(\mathrm{cm}^{-1}\right)\end{array}$ \\
\hline $758-765$ & $\omega \mathrm{CH}_{2}$ aromatic ring in styrene & \\
\hline 911 & $\begin{array}{l}\omega \mathrm{CH}_{2} \text { in vinyl butadiene and } \\
v_{17 \mathrm{~B}}\left(\mathrm{~B}_{2}\right) \text { mode in styrene }\end{array}$ & b911: 899-926 \\
\hline 966 & $\omega \mathrm{CH}$ in trans butadiene & Trans: 950-984 \\
\hline 994 & $\boldsymbol{\omega} \mathrm{CH}$ invinylbutadiene & \\
\hline 1029 & $v$ aromatic ring in styrene & \\
\hline 1070 & $v$ aromatic ring in styrene & \\
\hline 1156 & $v$ aromatic ring in styrene & \\
\hline 1183 & $v$ aromatic ring in styrene & \\
\hline 1313 & $\delta\left(=\mathrm{CH}_{2}\right)$ in trans butadiene & \\
\hline $1364-1344$ & $\omega \mathrm{CH}_{2}$ & \\
\hline 1419 & $\delta\left(=\mathrm{CH}_{2}\right)$ in vinyl butadiene & \\
\hline 1437 & $\delta_{\mathrm{s}} \mathrm{CH}_{2}$ in trans butadiene & \\
\hline 1453 & $\delta_{\mathrm{s}} \mathrm{CH}_{2}$ & \\
\hline 1494 & $v$ aromatic ring in styrene & \\
\hline 1583 & $v$ aromatic ring in styrene & \\
\hline 1602 & $v$ aromatic ring in styrene & styrene: $1595-1610$ \\
\hline 1640 & $v \mathrm{C}=\mathrm{C}$ in vinyl butadiene & vinyl: 1633-1645 \\
\hline 1668 & $\nu \mathrm{C}=\mathrm{C}$ trans butadiene & \\
\hline 1734 & $v \mathrm{C}=\mathrm{O}$ in carbonyl groups & CO: $1696-1765$ \\
\hline 1803 & Combination mode in styrene & \\
\hline 1870 & Combination mode in styrene & \\
\hline 1949 & Combination mode in styrene & \\
\hline 2237 & $\nu_{\mathrm{s}} \mathrm{C} \equiv \mathrm{N}$ acrylonitrile & CN: 2220-2260 \\
\hline 2848 & $\nu_{\mathrm{s}} \mathrm{CH}_{2}$ & \\
\hline 2922 & $\nu_{\text {as }} \mathrm{CH}_{2}$ & \\
\hline 2977 & $v_{\mathrm{s}}\left(\mathrm{CH}_{2}=\right)$ in vinyl butadiene & \\
\hline 3004 & $v \mathrm{CH}$ aromatic ring in styrene & \\
\hline 3027 & $v \mathrm{CH}$ aromatic ring in styrene & \\
\hline 3061 & $v \mathrm{CH}$ aromatic ring in styrene & \\
\hline 3083 & $v \mathrm{CH}$ aromatic ring in styrene & \\
\hline 3103 & $v \mathrm{CH}$ aromatic ring in styrene & \\
\hline
\end{tabular}

Many bands identified in FTIR spectra of ABS can be attributed to more than one absorbing group. Therefore, a few bands were chosen that can be attributed with a high degree of confidence to a specific absorbing unit and were used for mapping analysis. When several bands were attributed to the same unit, the most intense one was chosen. Table 2

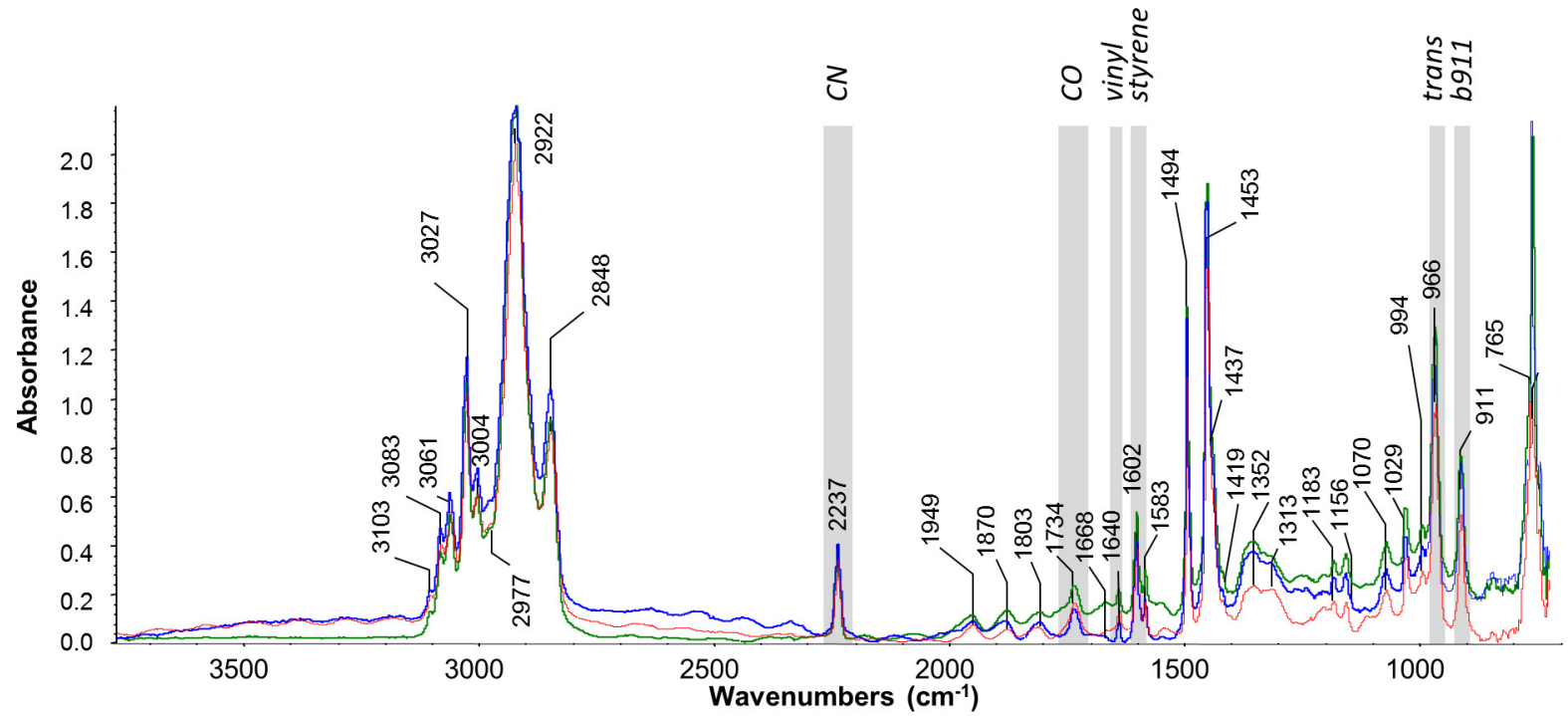

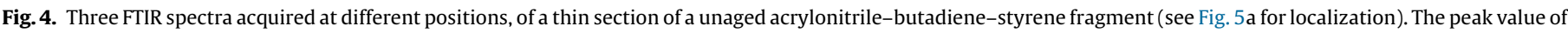
the main peaks is given (cf. Table 2 for assignment). 

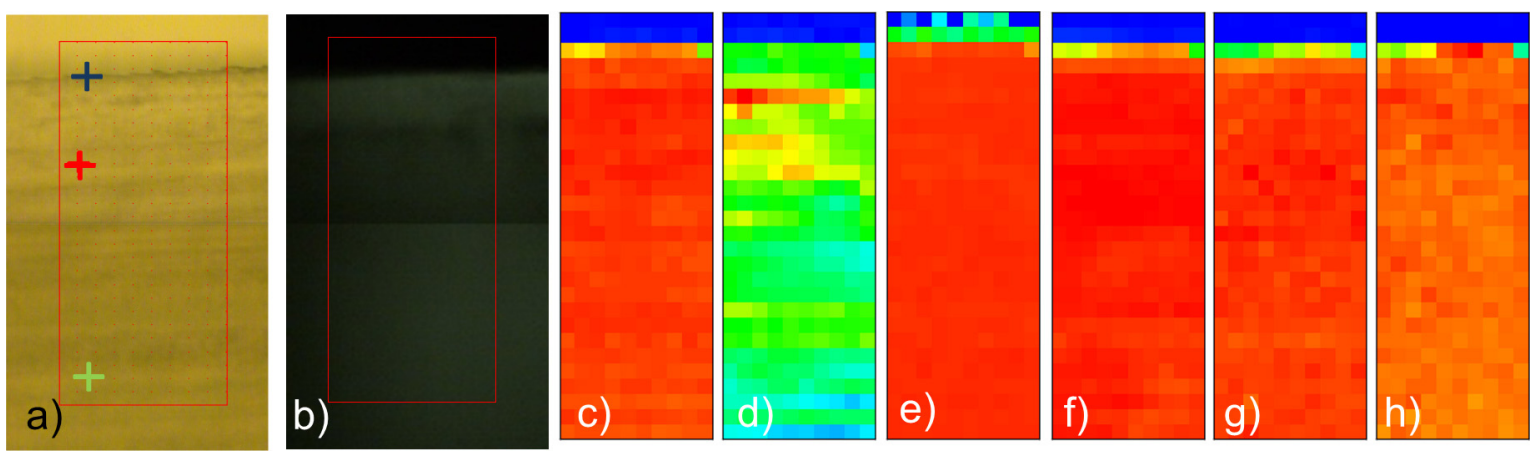

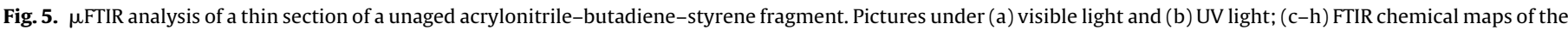

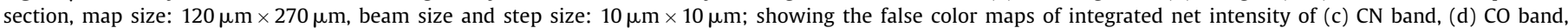
(e) vinyl-butadiene band, (f) styrene band, (g) trans-butadiene and (h) band at $911 \mathrm{~cm}^{-1}$.

indicates a list of ROI, which were used to map the net intensity of these main bands. The following bands from FTIR spectra were selected: the $\mathrm{CN}$ stretching at $2237 \mathrm{~cm}^{-1}$ for acrylonitrile; the stretching mode at $1602 \mathrm{~cm}^{-1}$ for styrene; the stretching mode of $\mathrm{CO}$ in carbonyl containing groups at $1734 \mathrm{~cm}^{-1}$. Polybutadiene is found in several configurations (cis, trans, vinyl) which can be differentiated due to specific bands [35,39].

- To identify cis-PB the intense peak corresponding to $v(\mathrm{CH}=\mathrm{CH})$ at $3004 \mathrm{~cm}^{-1}$ cannot be used since it interferes with a $v \mathrm{CH}$ aromatic ring band from styrene. Instead, the $\mathrm{C}=\mathrm{C}$ stretching mode at $1659 \mathrm{~cm}^{-1}$ can be used to differentiate cis from trans-butadiene since the trans isomer possesses a dipole moment equal to zero and consequently does not show $\mathrm{C}=\mathrm{C}$ stretching [37]. In the present study, the peak of the cis-butadiene at $1659 \mathrm{~cm}^{-1}$ was not detected while this peak is rather intense in a pure cis-polybutadiene. This demonstrates that the 1-4 butadiene is mainly present in the trans form in the studied samples.

- Trans-PB presents an intense band at $966 \mathrm{~cm}^{-1}$, which does not interfere with any of the other units of ABS [40].

- Vinyl-PB has a set of characteristic bands: the most intense band corresponds to the $\mathrm{CH}_{2}=$ wagging mode at $911 \mathrm{~cm}^{-1}$ and was used by Bokria to map the degradation of 1,2 butadiene units [8]. It is named here b911 (Table 2). Additionally, less intense bands at 994, 1419, 1640 and $2977 \mathrm{~cm}^{-1}$ allow the assessment of vinyl isomers. The one at $1640 \mathrm{~cm}^{-1}$ was chosen to calculate maps.

As seen from Fig. $5 c-h$, the bands characteristic of styrene, acrylonitrile and butadiene are homogeneously distributed. CO (Fig. 5d) is almost homogeneously distributed, with some slight variations found in depth, but without a particular concentration in the surface, showing the relatively uniform presence of ester groups in the polymeric blend.

\subsection{SR- $\mu$ FTIR spectra and maps of $100 \mathrm{~h}$ aged standard acrylonitrile- butadiene-styrene samples}

Fig. 6 summarizes the main results from the FTIR study of $100 \mathrm{~h}$ aged standard ABS.

With the exception of the first $10 \mu \mathrm{m}$, the intensity of acrylonitrile (Fig. 6d), styrene (Fig. 6f), trans (Fig. 6g) and vinyl (Fig. 6h) butadiene are relatively constant. Conversely, the CO map (Fig. 6c) reveals some oxidation at the surface of the sample.

To better visualize the evolution of oxidation, chemical profiles were calculated by averaging the map intensity along the width of the map. For a better readability, intensities were normalized to
1 in the bulk region (Fig. 6i). This figure confirms the results derived from the maps and highlights the fact that, after $100 \mathrm{~h}$, oxidation is limited to the first $\sim 30 \mu \mathrm{m}$. The CO map was used to select 10 points in the oxidized region (red spectrum in Fig. 6i) and 10 points in the bulk region (green spectrum in Fig. 6i). The main chemical modifications concern the decrease of the bands related to butadiene unsaturation $\left(2977,1640,966\right.$ and $\left.911 \mathrm{~cm}^{-1}\right)$ and the increase of the CO band at $1735 \mathrm{~cm}^{-1}$.

A slight increase of the absorption in the hydroxyl stretching domain (3600-3200 $\mathrm{cm}^{-1}$ ) can also be noted, and this band can be ascribed to the formation of carboxylic acids and alcohols [8]. It was mapped by calculating the net intensity in the region of interest: $3162-3623 \mathrm{~cm}^{-1}$ (Fig. $6 \mathrm{j}$ ). The integrated 1D profile of $\mathrm{OH}$ intensity is plotted in Fig. 8. To calculate this profile, the intensity of the hydroxyl band was normalized by the intensity of a band unaffected by photo-aging. Bokria proposes to use the $\mathrm{CN}$ band [8]; Figs. $5 \mathrm{c}, 6 \mathrm{~d}$ and $8 \mathrm{e}$, indeed confirm that $\mathrm{CN}$ remain constant during degradation. This normalization provides a means to correct for signal differences due to variation of thickness from one sample to another. Figs. $6 \mathrm{c}$ and 7 reveal that hydroxyls are specifically localized in the first $20 \mu \mathrm{m}$.

These two main results ( $\mathrm{CO}$ and $\mathrm{OH}$ distribution) agree with the observations made by Bokria et al. and by Nagle et al. during the thermo-oxidative degradation of hydroxy-terminated polybutadiene/isophorone diisocyanate polyurethane rubber [9].

In addition, a slight red shift of the signal relative to $v_{\mathrm{s}}$ and $v_{\mathrm{as}}$ $\mathrm{CH}_{2}$ groups (from 2848 to $2853 \mathrm{~cm}^{-1}$ and from 2922 to $2924 \mathrm{~cm}^{-1}$ respectively) was observed. This could reflect a disorganization of the polymer chain and an increase in the inter-chain aliphatic interactions [41].

\subsection{SR- $\mu F T I R$ spectra and maps of $500 \mathrm{~h}$ aged standard acrylonitrile-butadiene-styrene samples}

Fig. 8 summarizes the main results from the FTIR study of $500 \mathrm{~h}$ aged standard ABS. Results are very similar to those obtained on the sample aged for $100 \mathrm{~h}$. The CO map (Fig. 8f) shows a photo-oxidation in the first $20 \mu \mathrm{m}$, slightly more intense than after $100 \mathrm{~h}$ (maximum normalized intensity of 1.8 instead of 1.6 after $100 \mathrm{~h}$; Fig. 8c). Maps and profiles confirm that while butadiene's unsaturation is reduced, styrene and acrylonitrile functions remain unaltered (Fig. 8c). Oxidation is observed with the increase in hydroxyl bands which can be differentiated from the baseline variations (Fig. 8k) and can be mapped (Figs. 7 and $8 \mathrm{~d}$ ).

A similar red shift of the $\mathrm{CH}_{2}$ stretching bands is observed (from 2848 to $2853 \mathrm{~cm}^{-1}$ for the symmetric mode and from 2922 to $2925 \mathrm{~cm}^{-1}$ for the asymmetric one). 

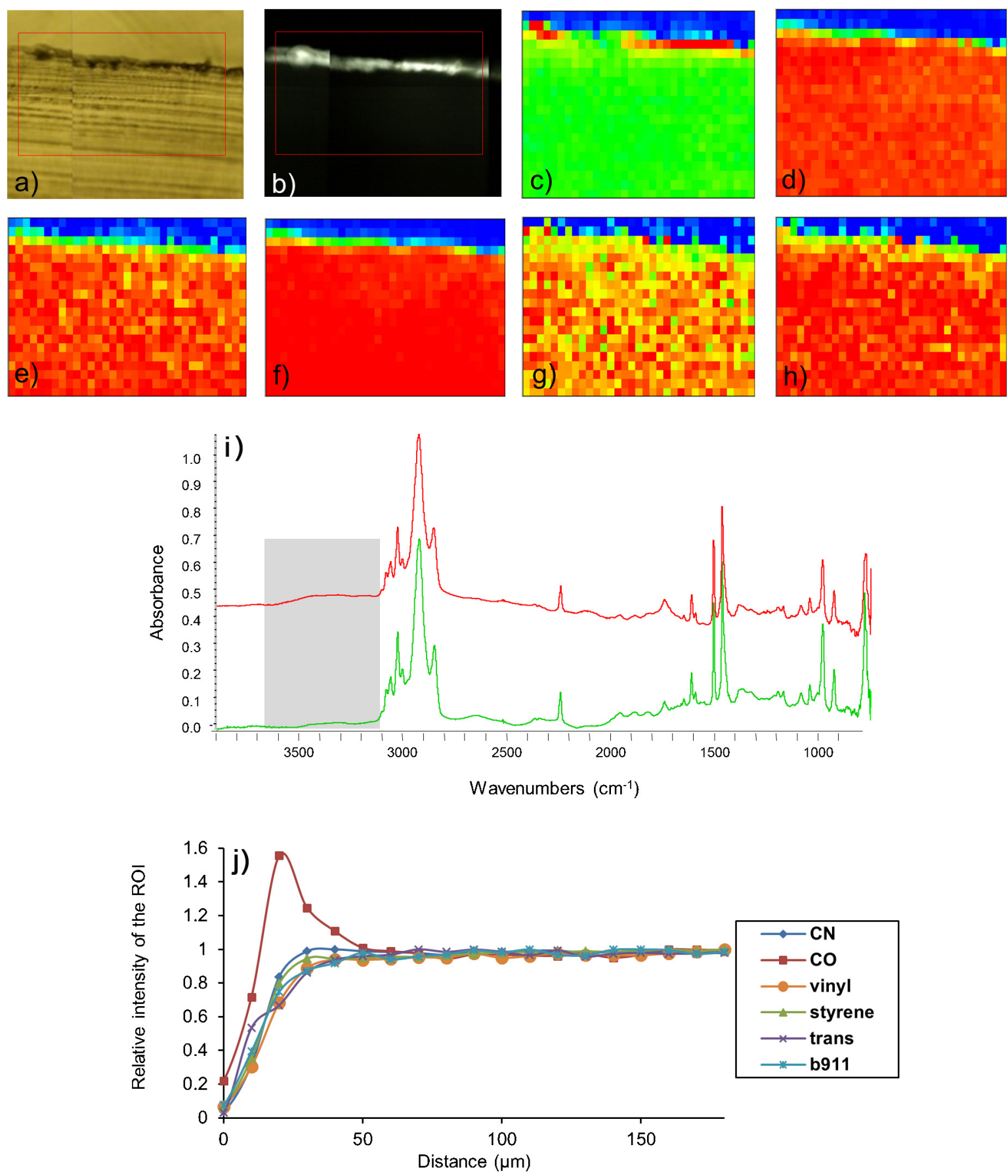

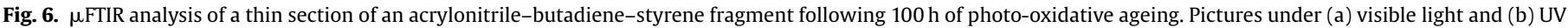

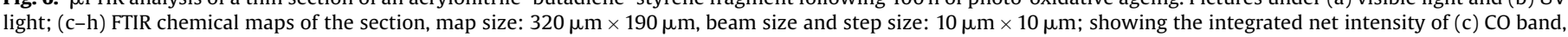

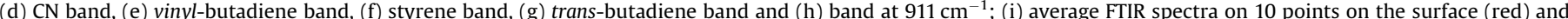

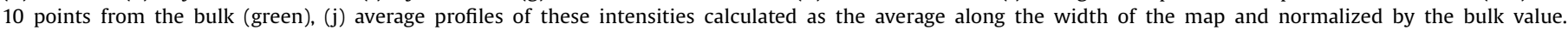
(For interpretation of the references to color in this figure legend, the reader is referred to the web version of this article.)

\subsection{SR- $\mu$ FTIR spectra and maps of $1000 \mathrm{~h}$ aged standard acrylonitrile-butadiene-styrene samples}

The $1000 \mathrm{~h}$ aged $A B S$ presents a more irregular surface than that seen in the $100 \mathrm{~h}$ and $500 \mathrm{~h}$ aged samples. The uppermost $\sim 30 \mu \mathrm{m}$ of the sample is discontinuous, ascribed to crazing in the material as seen in SEM analysis (Fig. 3).

FTIR mapping confirms that the degradation layer is thicker $(\sim 50 \mu \mathrm{m})$, with a higher intensity of the $\mathrm{CO}$ and $\mathrm{OH}$ bands (by a factor of five in comparison with the sample aged for $500 \mathrm{~h}$ )
(Figs. 7 and $9 \mathrm{c}-\mathrm{j}$ ), and a maximum of oxidation at $30 \mu \mathrm{m}$ from the surface. The bulk composition is found after $80 \mu \mathrm{m}$. Average spectra were calculated over regions of $210 \times 10 \mu \mathrm{m}^{2}$, every $10 \mu \mathrm{m}$, in depth and are plotted with the same scale in Fig. 9k.

Fig. 9c and i show that the b911 signal exhibits an intermediate plateau in the degraded region while vinyl- (Fig. 9g) and trans-butadiene signals (Fig. 9i) are almost undetected in this region. Bokria and Schlick observed similar differences in evolution of peak intensities during the photo-degradation of ABS [8]. They followed the relative intensity of the two peaks at 967 


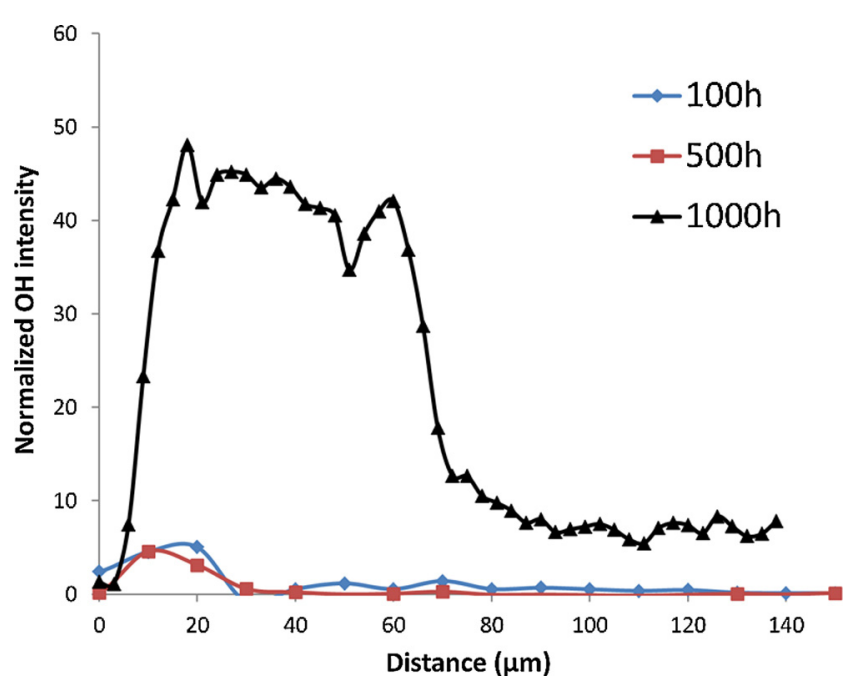

Fig. 7. Profile of the $\mathrm{OH}$ band intensity, normalized by the averaged $\mathrm{CN}$ band intensity in the bulk part of the sections, for acrylonitrile-butadiene-styrene aged for 100,500 and $1000 \mathrm{~h}$.

(corresponding to the "trans" group in our ROI list) and $911 \mathrm{~cm}^{-1}$ and observed that the decrease in the intensity of the $911 \mathrm{~cm}^{-1}$ peak is less pronounced than for the peak at $967 \mathrm{~cm}^{-1}$. This result was interpreted as the fact that "1,4 PB (trans or cis) is attacked preferentially compared to $1,2 \mathrm{~PB}$ (vinyl)", contrary to what was reported in two previous publications. This conclusion relied on the assignment of the peaks at 967 and $911 \mathrm{~cm}^{-1}$ to $1,4 \mathrm{~PB}$ and 1,2 PB respectively. However, the authors did not take into account the fact that PS also absorbs around $911 \mathrm{~cm}^{-1}$ (cf. Table 2), this band is hence not specific to vinyl-PB. Even if its intensity is lower, the band at $1640 \mathrm{~cm}^{-1}$ is a better alternative for the mapping of the distribution of vinyl-butadiene units. The set of spectra (Fig. 9k) as well as corresponding map (Fig. 9g) and profile (Fig. 9c) suggest that, both trans and vinyl-butadiene are equally subject to oxidation. By subtracting the spectrum of reference PS (data not shown), it clearly appears that the remaining absorption band at $911 \mathrm{~cm}^{-1}$, visible in the spectra from the most external regions (Fig. 9k) is attributed only to the styrene unit. From our results, it is clear that the band at $911 \mathrm{~cm}^{-1}$, even if intense, should not be considered as selective to vinyl-butadiene in samples containing styrene units.

Fig. 10a and b focus on two particular energy domains: $\mathrm{CH}$ stretching $\left(2800-3100 \mathrm{~cm}^{-1}\right)$ and $\mathrm{CO}$ stretching $\left(1620-1850 \mathrm{~cm}^{-1}\right)$, respectively. Fig. 11a shows that while aromatic $\mathrm{CH}$ peaks are not affected by the photo-degradation, the symmetric and asymmetric signal of aliphatic $\mathrm{CH}_{2}$ are clearly modified. This figure also shows the decrease of the vinyl absorption at $2977 \mathrm{~cm}^{-1}$.

Fig. 10b focuses on the CO domain. The initial peak at $1731 \mathrm{~cm}^{-1}$ becomes more intense, larger and slightly shifted to lower wavenumbers. The two main shoulders at 1775 and $1710 \mathrm{~cm}^{-1}$ can be attributed to $\mathrm{C}-\mathrm{O}$ stretch in anhydride/ g-lactone/peracids, and in carboxylic acids, respectively (Table 3 ). Additional bands at 1697 (aromatic ketones/acetophenone groups) and $1685 \mathrm{~cm}^{-1}$ ( $\alpha, \beta$-unsaturated carbonyls) cannot be excluded $[41,42]$. As shown in Fig. $9 \mathrm{~g}$, the vinyl peak $\left(1640 \mathrm{~cm}^{-1}\right)$ disappear in the surface region. A Gaussian fit of the bands using three principal bands at 1710,1731 and $1775 \mathrm{~cm}^{-1}$ demonstrates the contributions from (i) carboxylic acids and (ii) aliphatic esters, aldehyde stretching and (iii) anhydride/g-lactone and peracids respectively (Fig. 11).

In order to obtain a more detailed picture of the degradation layer, an additional map was acquired on the same sample, with beam size and step size of $10 \times 3 \mu \mathrm{m}^{2}$, over a region of $60 \times 138 \mu \mathrm{m}^{2}$. Maps were calculated and integrated as profiles. With this small aperture, the signal to noise ratio is poor below $1000 \mathrm{~cm}^{-1}$ due to diffraction. The trans-butadiene profile shows a jump, but is extremely noisy and was not included in Fig. 12 for more readability. The $\mathrm{OH}$ profile is shown in Fig. 7. Two profiles have been added to follow the red shift of $\nu_{\mathrm{s}}\left(\mathrm{CH}_{2}\right)$ during aging: profiles with peaks at 2846 (ROI $2840-2852 \mathrm{~cm}^{-1}$ ), and $2859 \mathrm{~cm}^{-1}$ (with ROI 2854-2865 $\mathrm{cm}^{-1}$ ). Figs. 11 and 12 show an interesting result: the different degradation features do not follow the same in-depth profile. All the modified species related to $\mathrm{CH}$ (peak 2846, peak 2859), CC (vinyl) and OH show a sharp knife edge at $\sim 70 \mu \mathrm{m}$, as do the new formed species (peak 2859 and $\mathrm{OH}$ ) which exhibit an homogeneous distribution in the debased region. Contrarily, the CO distribution, and more particularly the ester group, is peaked after $\sim 20 \mu \mathrm{m}$ and then shows a smooth decrease over $\sim 50 \mu \mathrm{m}$. These results suggest differences in the formation and/or the stability of the different degradation products. Additional analyses, in particular with UV-vis micro-spectroscopy will be needed to further investigate this different in-depth distribution of components.

As a conclusion, these results confirm the data reported in the literature [44]. There is a limit in the depth of maximum oxidation corresponding to $70 \mu \mathrm{m}$ regardless of the time of exposure. This strengthens the hypothesis that the layer of oxidized material acts as a protective shield against further photo-oxidative degradation processes (passivation) preventing oxygen diffusion and further UV penetration into the material $[8,45]$. However, crazing plays an important role in the formation of the layer of oxidized material.

Principal component analysis of multispectral images yield similar false color images based on spectral variations in the sample, and allow a rapid identification of oxidation layers without the need for the selection of specific spectral bands (see Supporting Information)

\subsection{Analysis of samples from historical objects made in acrylonitrile-butadiene-styrene}

In addition to the analysis of standard unaged and aged materials, fragments from two historical objects were examined in order to assess both the composition (in particular presence and distribution of additives) and the degradation of polymer.

As detailed below, fragments from the two objects show very heterogeneous composition. In both case, it was possible to find regions with a FTIR signature quite similar to the ABS reference. Fig. 13 compares spectra acquired on thin sections of our unaged ABS model, and of the two historical samples.

It confirms that ABS is the base constituent material of both objects. The FTIR spectra of samples from the Grillo telephone and the E63 lamp present characteristic peaks of ABS polymers, with slight variation of relative intensity. The main differences are the presence of two additional bands, one at $3301 \mathrm{~cm}^{-1}$ (assigned to a secondary amine), and one smaller, at $1565 \mathrm{~cm}^{-1}$ (assigned to a $\mathrm{NH}$ group); the peak at $1638 \mathrm{~cm}^{-1}$ is more intense than in reference ABS. A contribution from a carbonyl group, presumably an amide group, can be hypothesized, overlapping with the signal from ABS vinyl group. These features may indicate the presence of an additive (presumably a light or heat stabilizer) within the polymeric blend of both samples. For example reactive hindered amines are usually used as light stabilizers for ABS [46]. Little information is currently available regarding the specific history of stabilizers used in historical objects and warrants further and dedicated investigation. The telephone and the lamp presented different features which are described below. 

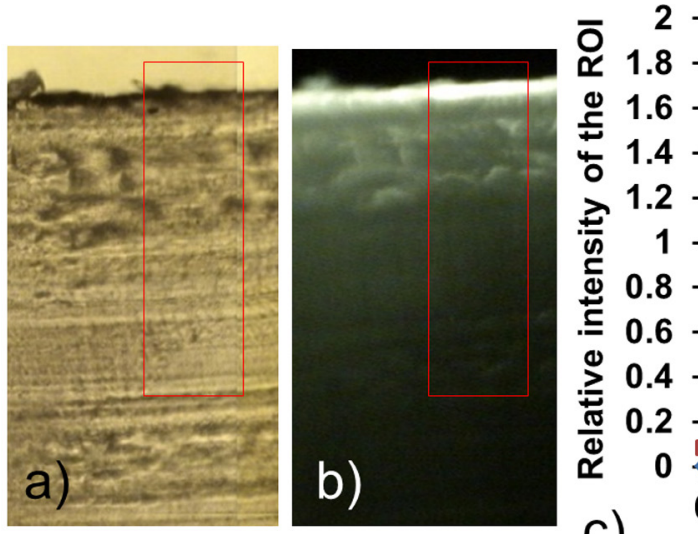

c)
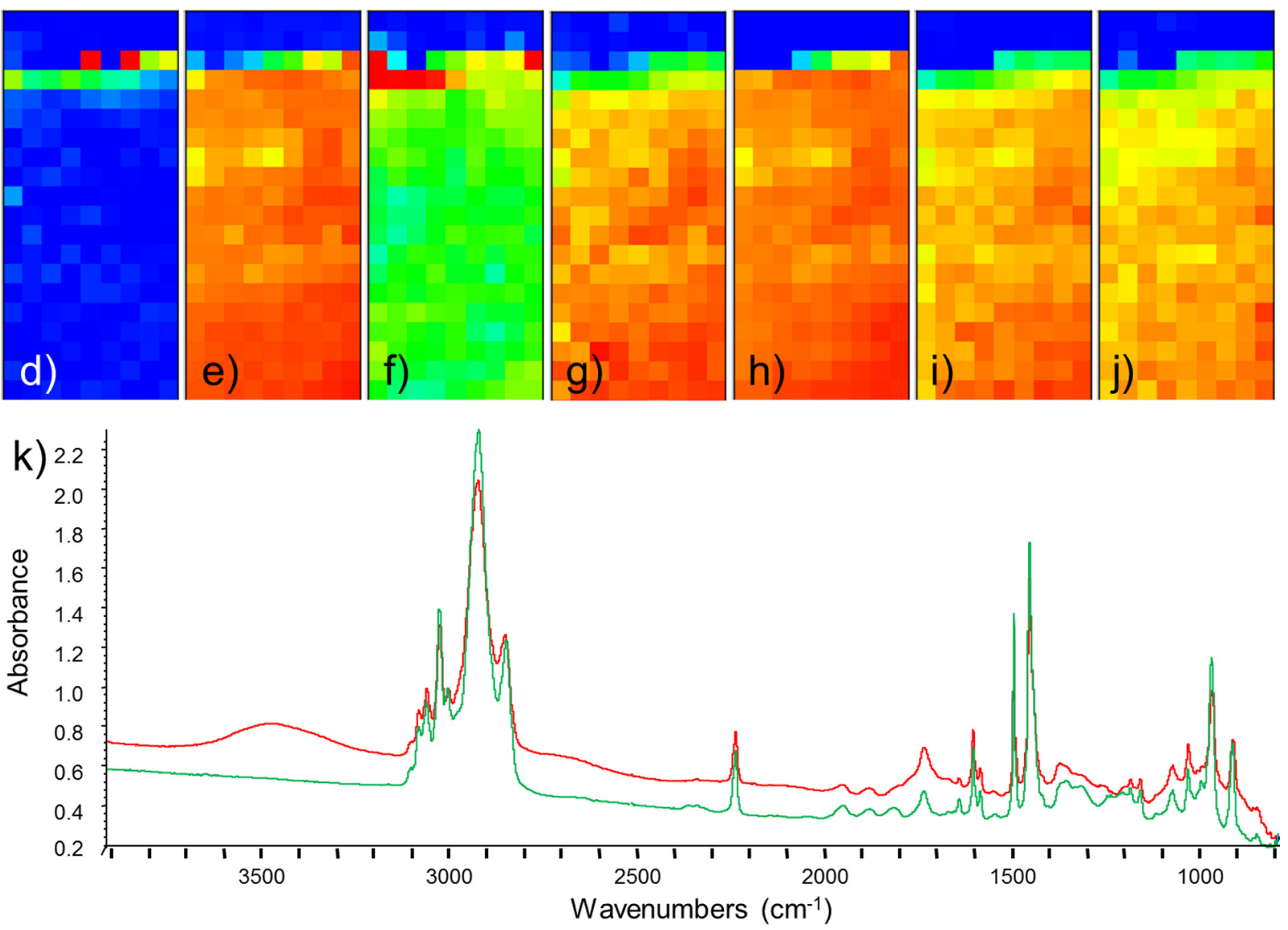

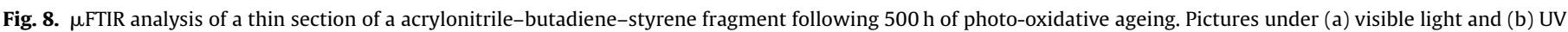

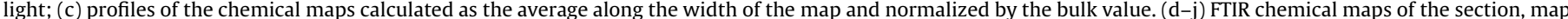

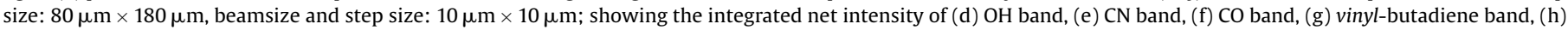

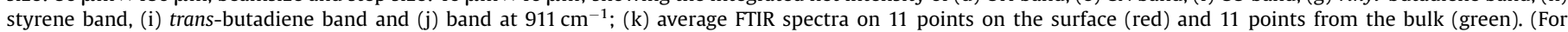
interpretation of the references to color in this figure legend, the reader is referred to the web version of this article.)

\subsubsection{Fragment from the E63 lamp}

Analysis of samples of E63 does not suggest any gradient in the degradation of the ABS in the sample. "OH map" (Fig. 14g) reveals a large hot spot, in the middle of ABS matrix. As seen in Fig. 14i, this does not correspond to photo-oxidation hydroxyls, the peak being sharper, and centered at lower wavenumbers $\left(3286 \mathrm{~cm}^{-1}\right)$, corresponding to $\mathrm{N}-\mathrm{H}$ stretching modes. An additional peak at $1656 \mathrm{~cm}^{-1}$ is also clearly noticed. These two peaks are attributed to an inclusion in the polymeric blend. To obtain a clearer identification of this additive, spectrum \#1 (average spectrum in the bulk part) was subtracted from spectrum \#2 (average spectrum in the inclusion). The result (spectrum \#3 in Fig. 14i) is characteristic of a proteinaceous compound with typical bands associated with amide A, at $\sim 3300 \mathrm{~cm}^{-1}$, amide $\mathrm{I}$ at $1650 \mathrm{~cm}^{-1}$ and amide II at $1550 \mathrm{~cm}^{-1}$. Comparison with library spectra gives zein as the best-match. Zein is characterized by a band at $3286 \mathrm{~cm}^{-1}$ from amide $A$, and in particular shows a strong signal at $1656 \mathrm{~cm}^{-1}$, which is related to a high alpha-helix content. The signal at $1620 \mathrm{~cm}^{-1}$ is present only as a weak shoulder, revealing a significantly lower percentage of $\beta$ sheet structures [47,48]. Zein is the major storage protein of maize and was proposed as a possible base material for polymer applications in the early 20th 

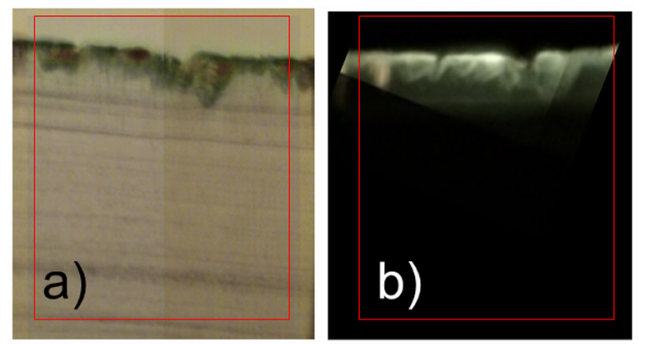

c)
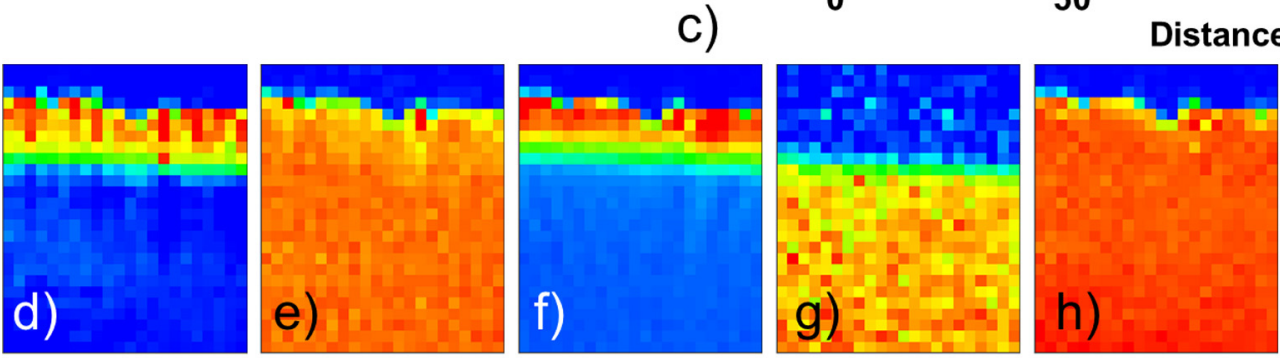

$(\mu \mathrm{m})$

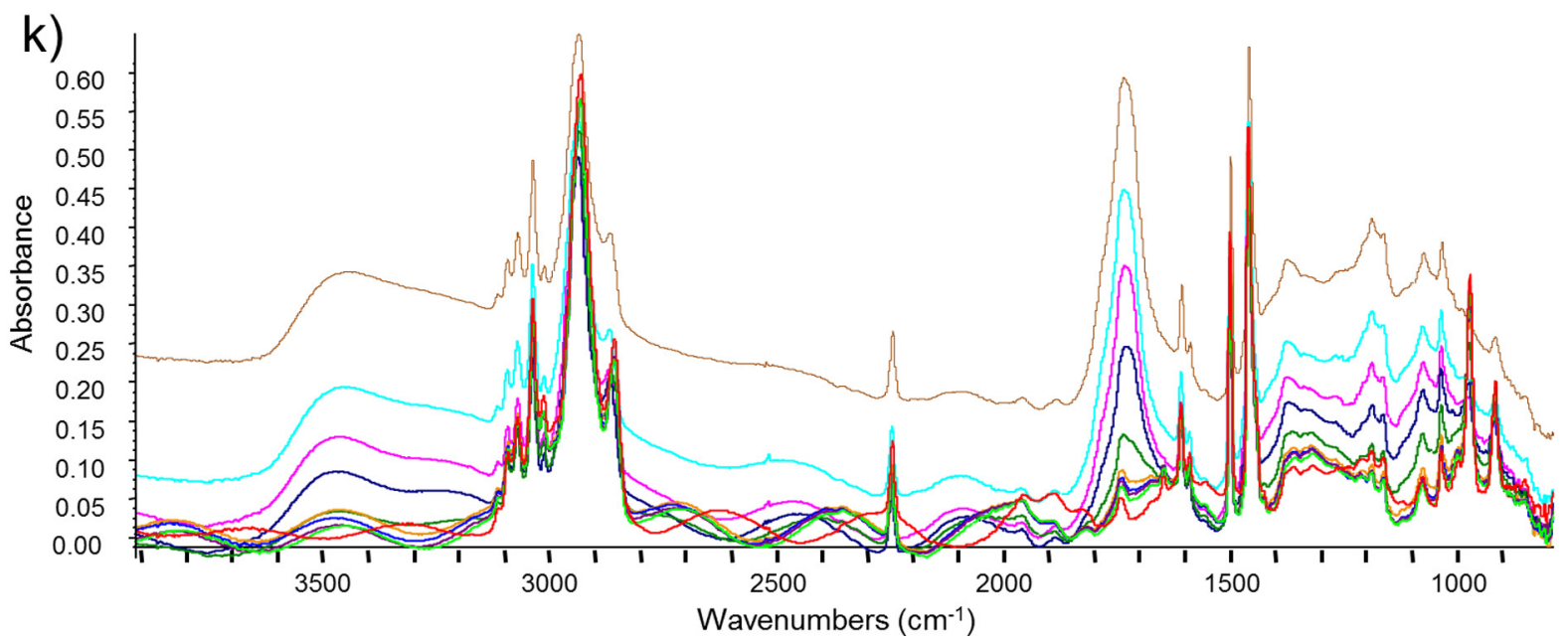

$0-10 \mu \mathrm{m}$

$10-20$ um

20-30um

$30-40 \mu \mathrm{m}$

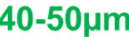

50-60 um

$60-70 \mu \mathrm{m}$

70-80um

$80-90 \mu \mathrm{m}$

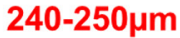

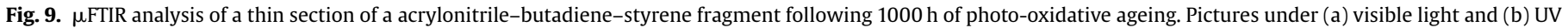

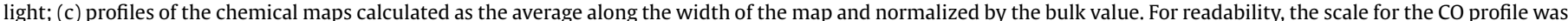

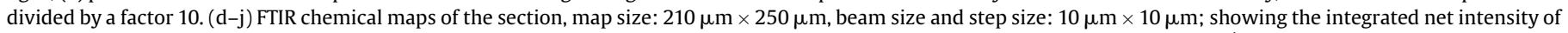

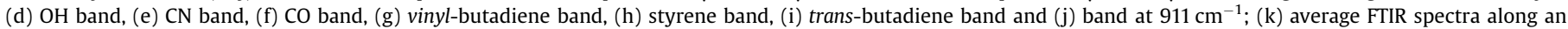
horizontal line, at different depths.

century. [49]. Several patents and papers published in the 1950-1960s reported the use of zein as an inclusion in polymers [47,50-52] and the first major commercial use of zein was for coatings, principally for its high abrasion resistance. In the E63 lamp, which was produced in 1963 , zein could have been used in a protective coating, or could have been present directly in the ABS formulation. There is no information about its use specifically as an additive for these objects and its presence as an inclusion in E63 is the first example of a proteinaceous compound identified in a historical plastic design object.

\subsubsection{Fragment from the Grillo telephone}

FTIR results obtained on a thin section of a fragment from the Grillo telephone are presented in Fig. 15.

The external part of the phone corresponds to the upper part of the fragment. From the maps, different regions could be identified and average spectra ( 5 pixels of $10 \times 10 \mu \mathrm{m}^{2}$ ) were calculated and are displayed in Fig. 15j. The spectrum from area 2 has been discussed above. The peak at $3301 \mathrm{~cm}^{-1}$ was mapped and shows a rather homogenous distribution (Fig. 15c). Spectrum from area 1 corresponds to the upper part of the section, and shows two main differences with spectrum 2: an increased intensity of $\mathrm{OH}$ stretching and of carbonyl stretching bands together with the characteristic shoulders of the oxidation products as described above for reference samples.

$\mathrm{OH}$ and $\mathrm{CO}$ distributions are imaged in Fig. 15b and e, respectively. These maps show that these two groups are also concentrated in the lower part of the section, where two averaged spectra were extracted: 3 and 4 . An area \#4, the signal is saturating, this explains the hot spot observed, in almost all maps.

A profile was calculated for all maps, along a line plotted in Fig. 15i (average on a width of $20 \mu \mathrm{m}$ ). Similarly to what was observed on model samples, $\mathrm{CN}$ and styrene groups have quite constant concentrations. The decrease on the upper side most 

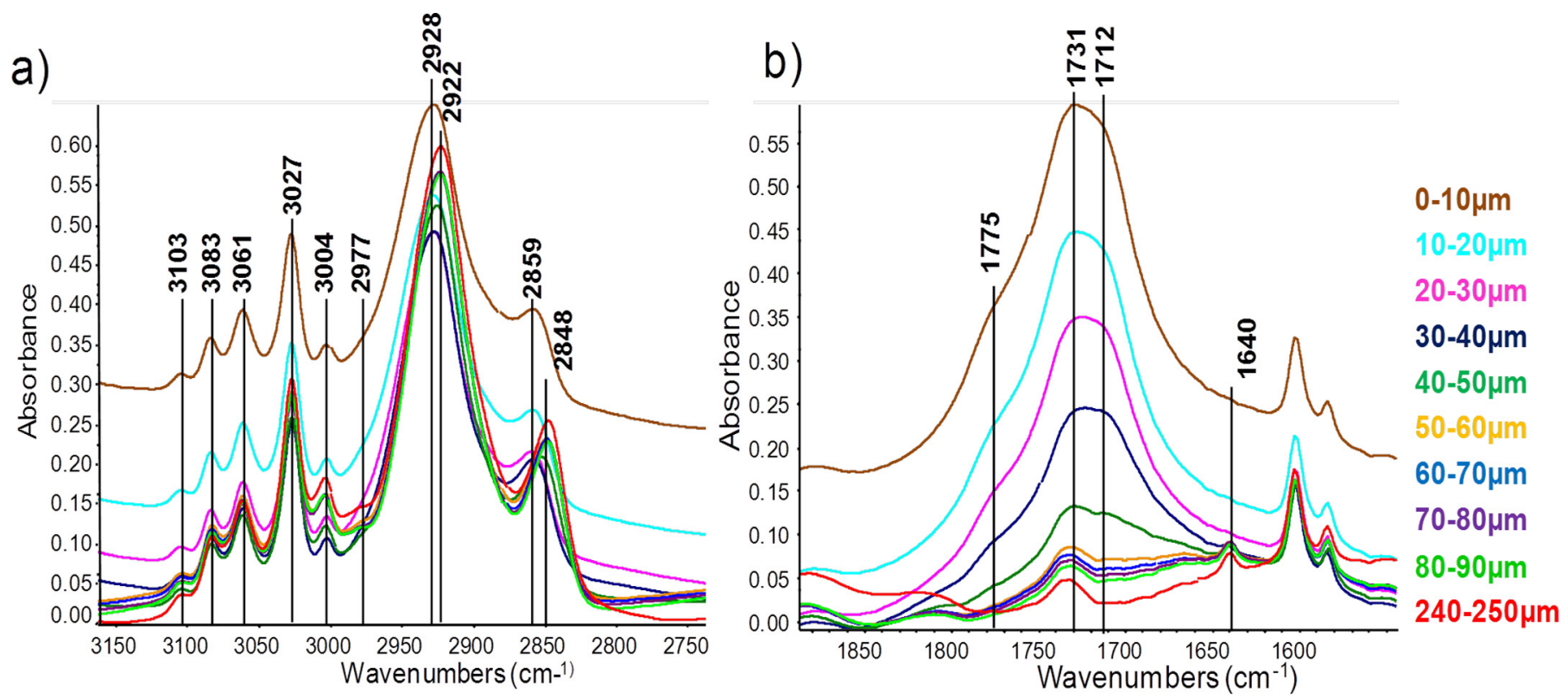

Fig. 10. $\mu$ FTIR spectra with zoom in (a) the $\mathrm{CH}$ stretch domain and (b) the $\mathrm{CO}$ stretch domain.

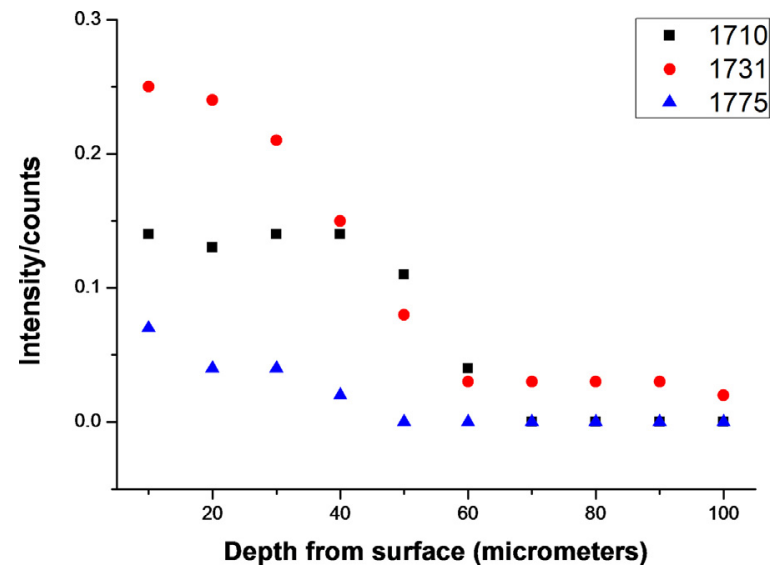

Fig. 11. A Gaussian fit using three principal bands at 1710,1731 and $1775 \mathrm{~cm}^{-1}$.
Table 3

Oxidation products which contributed to the band between 1719 and $1735 \mathrm{~cm}^{-1}$ in the first $192 \mu \mathrm{m}$ below the exposed surface $[6,42,43]$.

\begin{tabular}{ll}
\hline Peak $\left(\mathrm{cm}^{-1}\right)$ & Attribution \\
\hline 1699 & $\alpha, \beta$-Unsaturated ketone \\
1710 & Carboxylic acids \\
1720 & $\alpha, \beta$-Unsaturated aldehyde \\
1720 & Saturated ketone \\
1731 & Saturated aldehyde \\
1739 & Ester group \\
1775 & Anhydride/g-lactone/peracids \\
\hline
\end{tabular}

probably reflects changes in the section thickness. Indeed, fragments from historical objects are smaller, more precious, and more brittle than the model samples, therefore the preparation of thin sections with constant thickness was trickier. The profile of $\mathrm{CO}$, as well as FTIR spectra show that the degree of oxidation at the surface in the material is similar to that observed

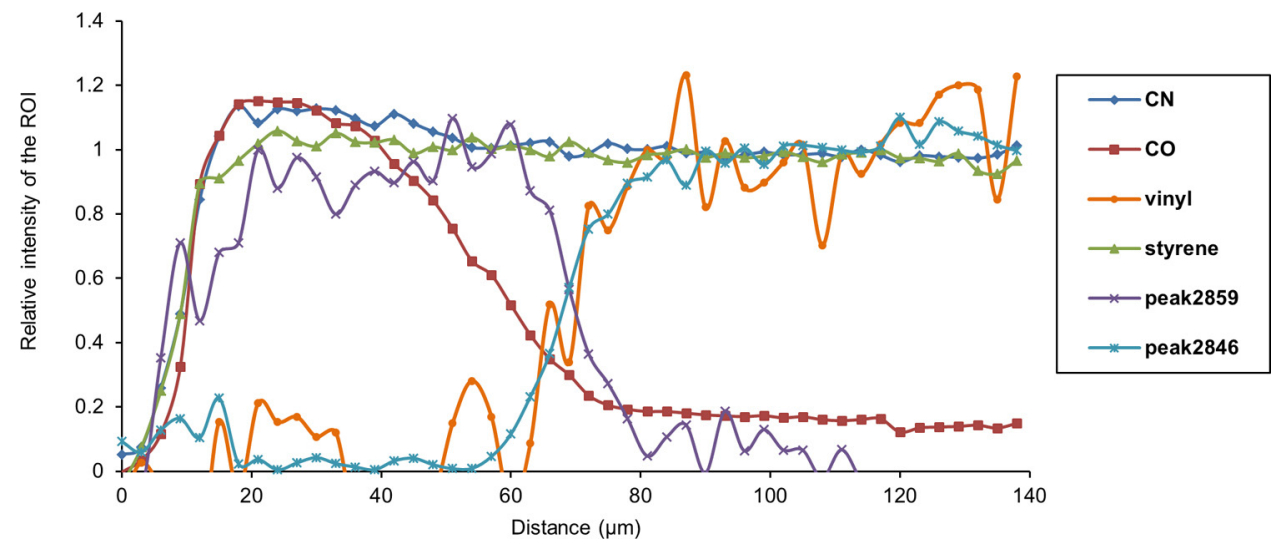

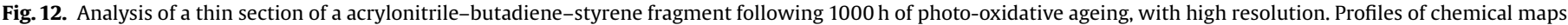

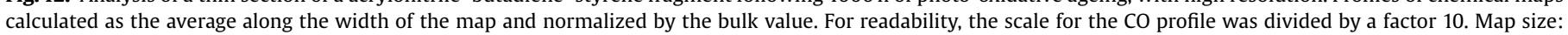
$60 \mu \mathrm{m} \times 138 \mu \mathrm{m}$, beam size and step size: $10 \mu \mathrm{m} \times 3 \mu \mathrm{m}$. 


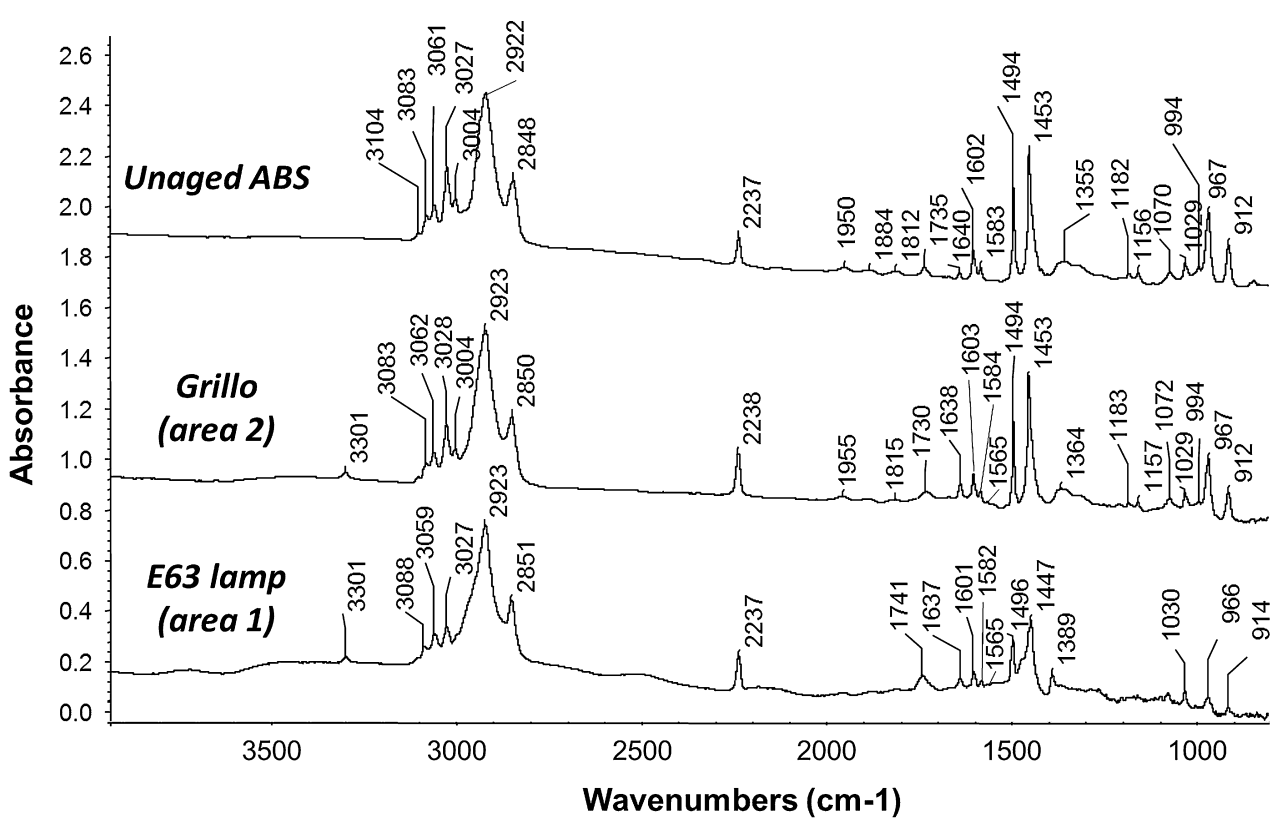

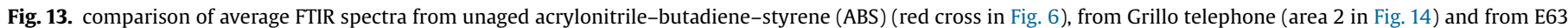
lamp (area 1 in Fig. 15).

on the surface of artificially aged ABS samples. Even if no quantitative information can be derived from so heterogeneous samples, the ABS sample aged during $1000 \mathrm{~h}$ is the one presenting the best match with the Grillo sample. Finally, the profile of vinyl group is quite different from results obtained on photo-aged samples. It is still present in area 1 and 3 , while it completely disappeared in most degraded areas of model photo-aged samples. Here the residual peak may be attributed to the additional presence of an amide group, from an additive, introduced in the historical polymer, but not present in our model ABS.

\section{Conclusions}

SR- $\mu$ FTIR microspectroscopy is an effective approach for the assessment of degradation of polymers, in particular ABS. The 2D microspectroscopy has allowed the high resolution mapping of photo-oxidation both in ABS standard and historical samples, providing means for the identification of different degradation products, the detection of inclusions and the assessment of in-depth degradation inside the material.

Correct sample preparation is of fundamental importance and represents the critical point for the success of analysis. Samples were prepared as free-resin thin-sections, avoiding over-absorption problems, resin interferences and allowing the fast registration of spectra with good SNR over large areas with a very high spatial resolution, up to $3 \mu \mathrm{m}$. For ABS standard a maximum level of oxidation was found in the first $70 \mu \mathrm{m}$ in depth. The intensity of the bands attributed to PB at 1639, 967 and $911 \mathrm{~cm}^{-1}$ decreases with depth, while the bands attributed to $\mathrm{C}=\mathrm{O}$ oxidation $\left(1719-1735 \mathrm{~cm}^{-1}\right)$ and the
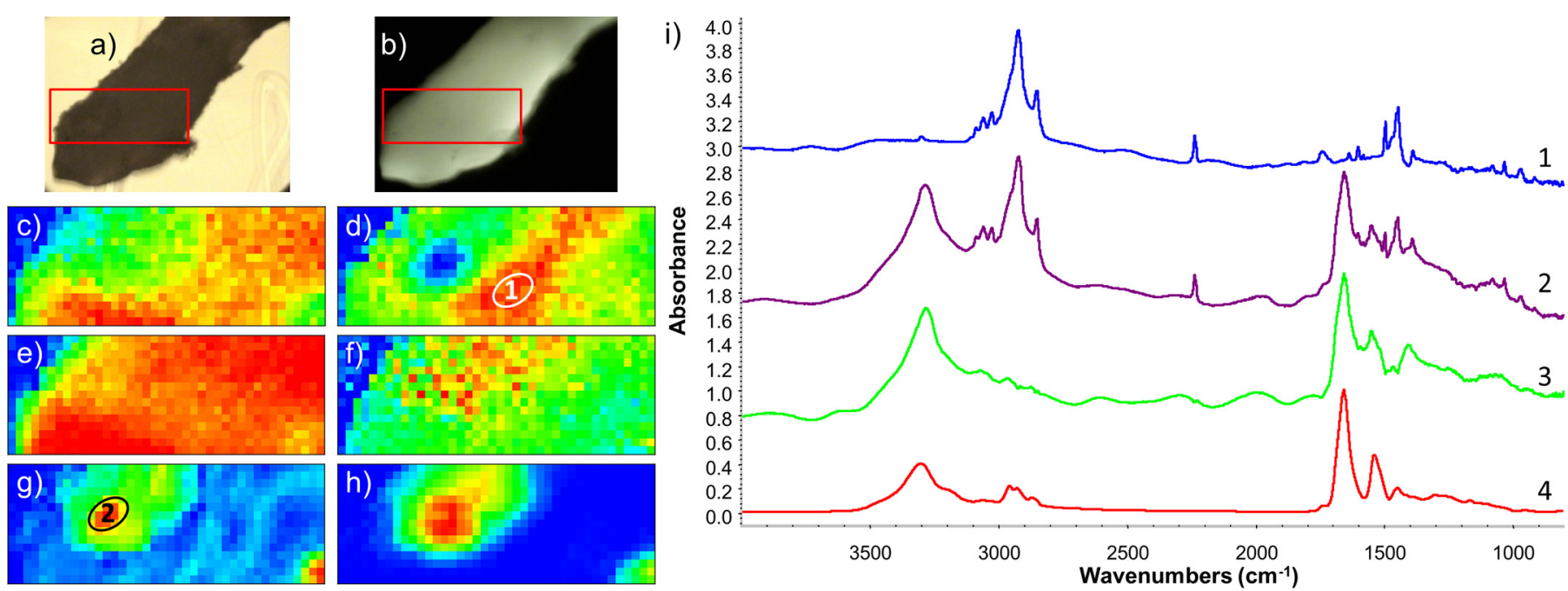

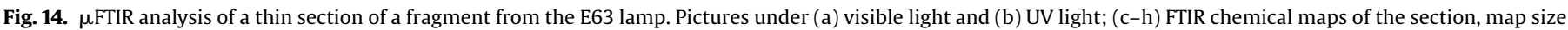

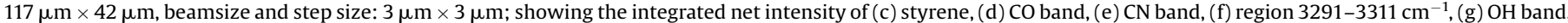

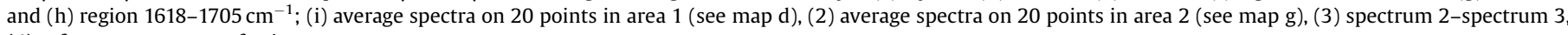
(4) reference spectrum of zein. 

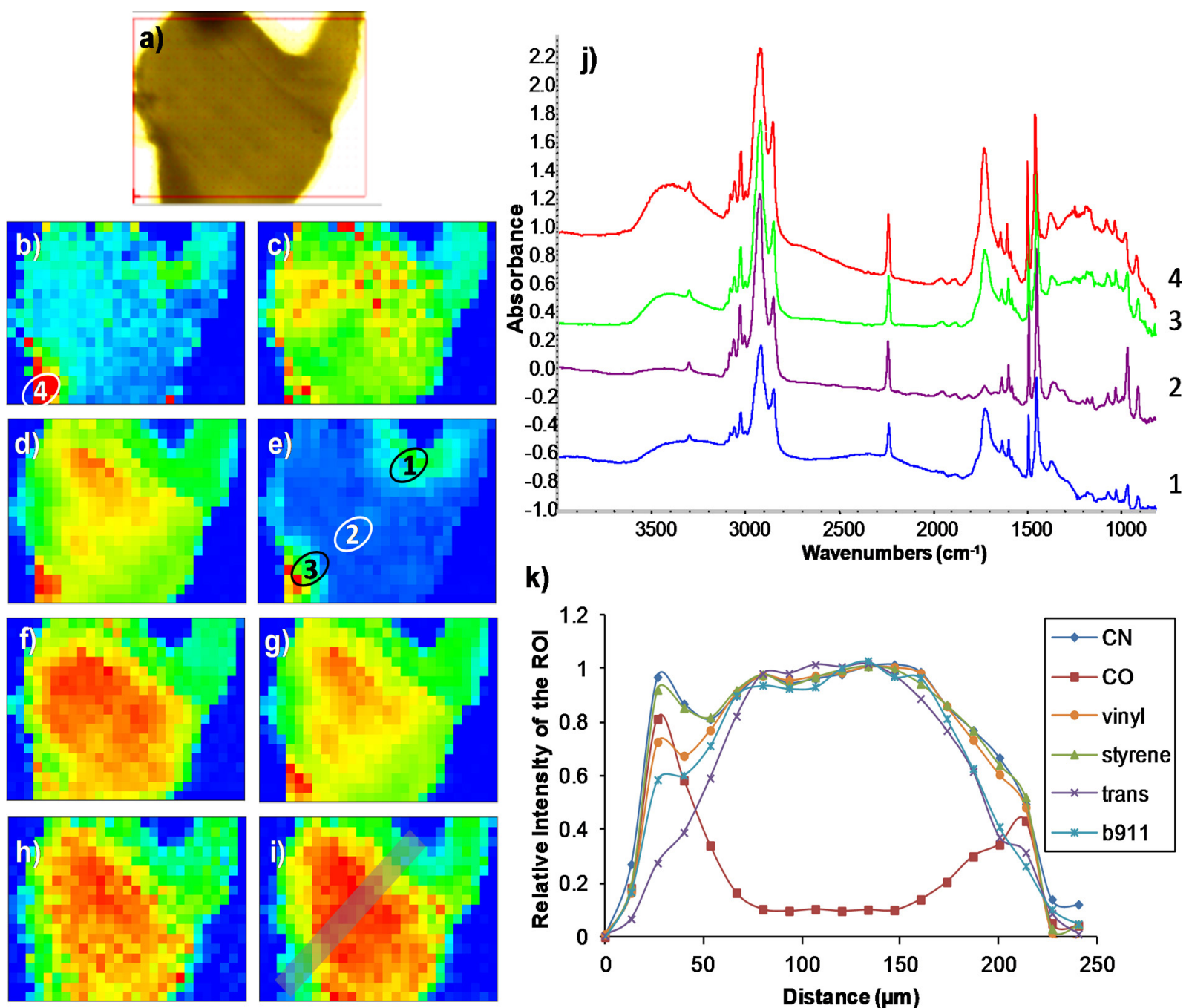

k)

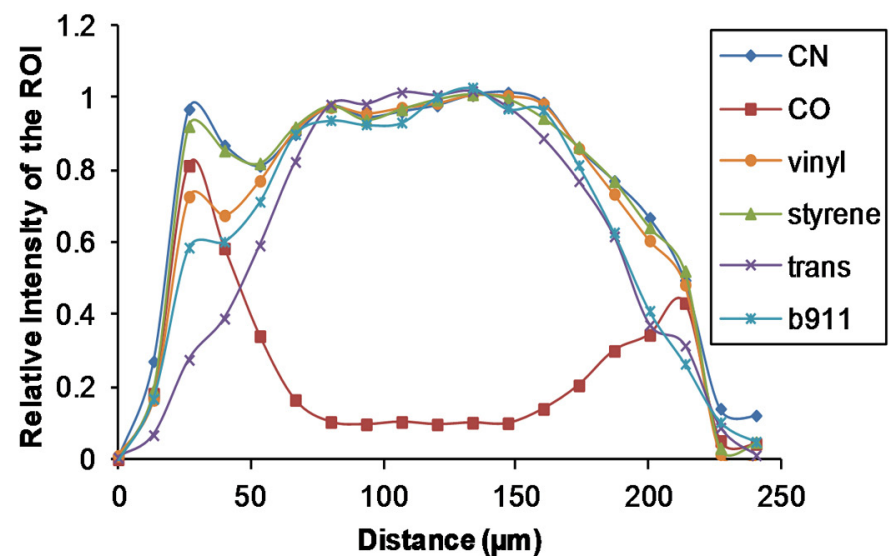

Fig. 15. $\mu$ FTIR analysis of a thin section of a fragment from the Grillo telephone. (a) Picture under visible light; (b-i) FTIR chemical maps of the section, map size: $260 \mu \mathrm{m} \times 180 \mu \mathrm{m}$, beam size and step size: $10 \mu \mathrm{m} \times 10 \mu \mathrm{m}$; showing the integrated net intensity of (b) OH band, (c) region $3291-3311 \mathrm{~cm}^{-1}$, (d) CN band, (e) CO band, (f) vinyl-butadiene band, (g) styrene band, (h) trans-butadiene band and (i) band at $911 \mathrm{~cm}^{-1}$; (j) average FTIR spectra on 5 points on 4 areas, represented in (e) and (b); (k) profiles of the chemical maps calculated as the average along the line represented in $(\mathrm{j})$ and normalized by the value in region 2 .

hydroxyls (3200-3600 $\mathrm{cm}^{-1}$ ) increase, as a consequence of the formation of free radicals ( $\mathrm{R}$ and $\mathrm{ROO}^{\bullet}$ ) or hydroperoxides. The chemoselectivity for 1,4 over $1,2 \mathrm{C}=\mathrm{C}$ of $\mathrm{PB}$ proposed by Bokria and Schlick is not confirmed. The high resolution mapping allowed revealing a different in-depth distribution of degradation products (carbonyl and hydroxyls).

\section{Acknowledgment}

The authors thank arch. Davide Galletta for his precious collaboration. These experiments were performed on the ID21 beamline at the European Synchrotron Radiation Facility (ESRF), Grenoble, France (experiment \#EC-977).

\section{Appendix A. Supplementary data}

Supplementary data associated with this article can be found, in the online version

\section{References}

[1] T. Van Oosten, Y. Shashoua, F. Waentig, Plastics in Art: History, Technology, Preservation, Siegl, Munchen, 2002.
[2] I. Shashoua, Conservation of Plastics: Materials Science, Degradation and Preservation, Elsevier, Oxford, 2008.

[3] M. Nečemer, P. Kump, P. Sket, J. Plavec, J. Grdadolnik, M. Zvanut, A novel analytical technique suitable for the identification of plastics, Acta Chim. Slov. 60 (3) (2013) 701-705.

[4] G. Pastorelli, T. Trafela, P.F. Taday, A. Portieri, D. Lowe, K. Fukunaga, M. Strlič Characterisation of historic plastics using terahertz time domain spectroscopy and pulsed imaging, Anal. Bioanal. Chem. 403 (5) (2012) 1405-1414.

[5] M.E. Adams, D.J. Buckley, R.E. Colborn, Acrylonitrile-butadiene-styrene, Rapra Rev. Rep. 6 (10) (1993) Report 70.

[6] R.M. Santos, G.L. Botelho, A.V. Machado, Artificial and natural weathering of ABS, J. Appl. Polym. Sci. 116 (2010) 2005-2014.

[7] M. Piton, A. Rivaton, Photo-oxidation of ABS 300 at long wavelengths, Polym. Degrad. Stab. 55 (2) (1997) 147-157.

[8] J.G. Bokria, S. Schlick, Spatial effects in the photodegradation of poly acrylonitrile-butadiene-styrene): a study by ATR-FTIR, Polymer 43 (11) (2002) 3239-3246.

[9] D.J. Nagle, J. Dylan, M. Celina, L. Rintoul, P.M. Fredericks, Infrared microspectroscopic study of the thermo-oxidative degradation of hydroxyterminated polybutadiene/isophorone diisocyanate polyurethane rubber, Polym. Degrad. Stab. 92 (8) (2007) 1446-1454.

[10] R.J. Schexnaydre, B.S. Mitchell, Synchrotron infrared microspectroscopy characterization of heterogeneities in solid-state blended polymers, Mater. Lett. 62 (2007) 2151-2155.

[11] M.J. Nasse, M.W. Walsh, E.C. Mattson, R. Reininger, A. Kajdacsy-Balla, V. Macias, R. Bhargava, C.J. Hirschmugl, High-resolution Fourier-transform infrared chemical imaging with multiple synchrotron beams, Nat. Methods 8 (2011) 413-416.

[12] P. Dumas, N. Jamin, J.L. Teillaud, L.M. Miller, B. Beccard, Imaging capabilities of synchrotron infrared microspectroscopy, Faraday Dis. 126 (2004) 289-302. 
[13] M. Unger, E. Mattson, C. Schmidt Patterson, Z. Alavi, D. Carson, C.J. Hirschmugl, Synchrotron-based multiple-beam FTIR chemical imaging of a multi-layered polymer in transmission and reflection: towards cultural heritage applications, Appl. Phys. A 111 (2013) 135-145.

[14] P. Dumas, L.M. Miller, The use of synchrotron infrared microspectroscopy in biological and biomedical investigations, Vib. Spectrosc. 32 (19) (2003) 21.

[15] E.A. Carter, K.K. Tam, R.S. Armstrong, P.A. Lay, Vibrational spectroscopic mapping and imaging of tissues and cells, Biophys. Rev. 1 (2) (2009) 95-103.

[16] H.Y.N. Holman, Synchrotron infrared spectromicroscopy for studying chemistry of microbial activity in geologic materials, Dev. Soil Sci. 34 (2010) 103-130.

[17] N. Guilhaumoua, V. Sauttera, P. Dumas, Synchrotron FTIR microanalysis of volatiles in melt inclusions and exsolved particles in ultramafic deep-seated garnets, Chem. Geol. 223 (2005) 82-92.

[18] L. Bertrand, M. Cotte, M. Stampanoni, M. Thoury, F. Marone, S. Schöder, Development and trends in synchrotron studies of ancient and historical materials, Phys. Rep. 519 (2012) 51-96.

[19] M. Cotte, P. Dumas, Y. Taniguchi, E. Checroun, P. Walter, J. Susini, Recent applications and current trends in cultural heritage science using synchrotronbased Fourier transform infrared micro-spectroscopy, Comptes Rendus de physique de l'Académie des Sci. 10 (2009) 590-600.

[20] C.A. Melendres, Synchrotron infrared spectroscopy of electrode surfaces and interfaces, Synchrotron Radiat. News 11 (1998) 3.

[21] M.J. Vasquez, G.P. Halada, C.R. Clayton, The application of synchrotron-based spectroscopic techniques to the study of chromate conversion coatings, Electrochim. Acta 47 (19) (2002) 3105-3115.

[22] G. Ellis, Synchrotron IR microspectroscopy: opportunities in polymer science, IOP Conf. Ser. Mater. Sci. Eng. 14 (2010) 1-9.

[23] S.Y. Sankhe, D.E. Hirt, Characterization of erucamide profiles in multilayer linear low-density polyethylene and propylene-ethylene copolymer films using synchrotron-based FT-IR microspectroscopy, Appl. Spectrosc. 56 (2) (2002) 205-211.

[24] G. Ellis, C. Marco, M.A. Gòmez, E.P. Collar, J.M. Garcìa-Martinez, The study of heterogeneous polymer systems by synchrotron infrared microscopy, J. Macromol. Sci. 43 (2004) 253-266.

[25] J.P. Veder, K. Patel, G. Clarke, E. Grygolowicz-Pawlak, D.S. Silvester, R. De Marco, E. Pretsch, E. Bakker, Synchrotron radiation/Fourier transform-infrared microspectroscopy study of undesirable water inclusions in solid-contact polymeric ion-selective electrodes, Anal. Chem. 82 (14) (2010) 6203-6207.

[26] S. Ling, Z. Qi, D.P. Knight, Z. Shao, X. Chen, FTIR imaging, a useful method for studying the compatibility of silk fibroin-based polymer blends, Polym. Chem. 4 (2013) 5401-5406.

[27] A. Lluveras-Tenorio, A. Andreotti, I. Bonaduce, S. Boularand, M. Cotte, J. Roquè, M.P. Colombini, M. Vendrell-Saz, Mass spectrometric and synchrotron radiation based techniques for the identification and distribution of painting materials in samples from paints of Josep Maria Sert, Chem. Cent. J. 6 (2012) 45.

[28] M. Cotte, E. Checrou, V. Mazel, V.A. Solè, P. Richardin, Y. Taniguchi, P. Walter, J. Susini, Combination of FTIR and X rays synchrotron-based micro imaging techniques for the study of ancient paintings, e-Preserv. Sci. 6 (2009) 1-9.

[29] E. Pouyet, A. Lluveras-Tenorio, A. Nevin, D. Saviello, F. Sette, M. Cotte, Preparation of thin-sections of painting fragments: classical and innovative strategies, Anal. Chim. Acta 822 (2014) 51-59.

[30] J. Susini, M. Cotte, K. Scheidt, O. Chubar, F. Polack, P. Dumas, Technical report: the FTIR spectro-microscopy end-station at the ESRF-ID21 beamline, Synchrotron Radiat. News 20 (2007) 13-16.
[31] V.A.Solé,E.Papillon,M.Cotte,P.H.Walter,J.Susini,Amultiplatformcodefor the analysisofenergy-dispersiveX-rayfluorescencespectra,Spectrochim. ActaPartB 62(2007)63-68.

[32] X. Jouan, J.L. Gardette, Photo-oxidation of ABS: part 2-origin of the photo discoloration on irradiation at long wavelengths, Polym. Degrad. Stab. 36 (1) (1992) 91-96.

[33] D.C. Wright, Failure of polymer products due to photo-oxidation, Rapra Rev. Rep. 11 (9) (2001) Report 129.

[34] S.B. Munteanua, C. Vasile, Spectral and thermal characterization of styrenebutadiene copolymers with different architectures, J. Opt. Adv. Mat. 6 (2005) 3135-3148.

[35] R.A. Nyquist, C.L. Putzig, M.A. Leugers, R.D. McLachlan, B. Thill, Comparison of the vibrational spectra and assignments for $\alpha$-syndiotactic, $\beta$-syndiotactic, isotactic, and atactic polystyrene and toluene, Appl. Spectrosc. 46 (6) (1992) 981-987.

[36] P. Nallasamy, P.M. Anbarasan, S. Mohan, Vibrational spectra and assignments of cis- and trans-1,4-polybutadiene, Turk J. Chem. 26 (2002) 105-111.

[37] E.K. Karahaliou, P.A. Tarantili, Stability of ABS compounds subjected to repeated cycles of extrusion processing, Polym. Eng. Sci. 49 (11) (2009) 2269-2275.

[38] J. Guilment, L. Bokobza, Determination of polybutadiene microstructures and styrene-butadiene copolymers composition by vibrational techniques combined with chemometric treatment, Vib. Spectrosc. 26 (1) (2001) 133-149.

[39] B.S. Munteanu, M. Brebu, C. Vasile, Thermal behaviour of binary and ternary copolymers containing acrylonitrile, Polym. Degrad. Stab. 98 (9) (2013) 1889-1897.

[40] E. Gatebe, H. Herron, R. Zakeri, P. Ramiah Rajasekaran, S. Aouadi, P. Kohli, Synthesis and characterization of polydiacetylene films and nanotubes, Langmuir 24 (20) (2008) 11947-11954.

[41] N.S. Allen, A. Barcelona, M. Edge, A. Wilkinson, C.G. Merchan, V. Ruiz Santa Quiteria, Thermal and photooxidation of high styrene-butadiene copolymer (SBC), Polym. Degrad. Stab. 86 (1) (2004) 11-23.

[42] N.S. Allen, C. Luengo, M. Edge, A. Wilkinson, M.D. Parellada, J.A. Barrio, V. Ruiz Santa Quiteria, Photo-oxidation of styrene-ethylene-butadiene-styrene (SEBS) block copolymer, JPPA 162 (1) (2004) 41-51.

[43] Y.S. Duh, T.C. Ho, J.R. Chenn, C.S. Chao, Study on exothermic oxidation of acrylonitrile-butadiene-styrene (ABS) resin powder with application to ABS, Polymers 2 (3) (2010) 174-187.

[44] D.M. Kulich, S.K. Gaggar, Weathering of acrylonitrile butadiene styrene plastics: compositional effects on impact and color. Polymer durability: degradation, stabilization, and lifetime prediction, (1993), 483-501.

[45] S.K. Sharma, A. Mudhoo, Handbook of Applied Biopolymer Technology (RSC Green Chemistry), RSC Publishing, 2011.

[46] R.T. Kazmierczak, L.R. Mac, Reactive hindered amine light stabilizers, Patent US W01990009408 A1 (1989).

[47] D.J. Sessa, K.K. Woods, Purity assessment of commercial zein products after purification, J. Am. Oil Chemists' Soc. 88 (7) (2011) 1037-1043.

[48] L.A. Forato, T.C. Bicudo, L.A. Colnago, Conformation of alpha zein in solid state by Fourier transform IR, Biopolymers 72 (6) (2003) 421-426.

[49] J.R. Dann, J.W. Gates, B.D. Ihingsworth, Water-soluble protein resin copolymer, Patent US 2763625 (1956).

[50] S. Morimoto, Y. Akira, O. Masamichi, Graft copolymer containing spinnablesolution and method for preparing and spinning thereof, Patent US3104154 (1963).

[51] M.D. Ali, H.F. Mark, R.B. Mesrobian, Creep behavior of plasticized polyvinyl chloride liquid polymer plasticizers, Ind. Eng. Chem. 42 (3) (1950) 484-488.

[52] T.H. Shepherd, Surface treatment and bonding of organic high polymers, US Patent 3326742 (1967). 